\title{
A new method for the estimation of sinking particle fluxes from measurements of the particle size distribution, average sinking velocity, and carbon content
}

\author{
Andrew M. P. McDonnell ${ }^{1,2^{*}}$ and Ken O. Buesseler ${ }^{1}$ \\ ${ }^{1}$ Marine Chemistry and Geochemistry Department, Woods Hole Oceanographic Institution, Woods Hole, MA, USA 02543 \\ ${ }^{2}$ Institute of Biogeochemistry and Pollutant Dynamics, ETH Zürich, Universitätstrasse 16, 8092 Zürich, Switzerland
}

\begin{abstract}
We describe a new method for estimating sinking particulate carbon fluxes at high spatial and temporal resolutions from measurements of the particle concentration size distribution taken with an in situ camera system, in this case an autonomous video plankton recorder (VPR). Paired measurements of polyacrylamide gel traps and the VPR result in depth- and size-resolved parameterizations of the average sinking velocity, which enable the estimation of the flux size distribution from the concentration size distribution. Comparisons between the gel traps and the bulk carbon flux allows for the parameterization of the particle carbon content as a function of size. Together, these parameterizations permit the estimation of carbon fluxes from high-resolution VPR surveys. This method enables greater spatial, vertical, and temporal resolution of flux measurements beyond what is possible with conventional sediment traps. We tested this method in the Sargasso Sea and found that it was capable of accurately reproducing the fluxes measured in sediment traps while offering substantial improvement in the accuracy of the estimated fluxes compared to previous global and regional parameterizations. Our results point to the importance of local calibrations of the average sinking velocity and particle carbon content when estimating carbon fluxes from measurement of the concentration size distribution. This method holds important oceanographic potential for elucidating regional or basin scale carbon flows and providing new mechanistic insights into the function of the biological pump.
\end{abstract}

The persistent rain of marine particles sinking from the euphotic zone to greater depths is a dominant component of the ocean's biological pump. The magnitude of particle fluxes at the base of the euphotic zone as well as the scaling of these fluxes with respect to depth are important parameters that

*Corresponding author: E-mail: andrew.mcdonnell@env.ethz.ch

\section{Acknowledgments}

We are grateful to the captains, crews, and scientific personnel of the R/V Atlantic Explorer for their support during our cruises. Scott Gallager, Mick Follows, Phoebe Lam, Carl Lamborg, and Phil Boyd provided comments and suggestions on early versions of the manuscript while James Valdes made possible much of the underwater instrumentation associated with the drifting sediment trap array. Thanks to Stephanie Owens, Steven Pike, and Kelsey Collasius for their sampling efforts during the cruises. We thank Associate Editor Benitez-Nelson and three anonymous reviewers for their constructive reviews that greatly improved the quality of this manuscript. This project was made possible through funding from the National Science Foundation Carbon and Water Program (06028416), the Woods Hole Oceanographic Institution Academic Programs Office, ETH Zürich, and the Scurlock Bermuda Biological Station for Research Fund.

DOI 10.4319/lom.2012.10.329 impact the distributions of carbon and other biogeochemically important elements throughout the oceans (Yamanaka and Tajika 1996; Howard et al. 2006; Matsumoto 2007; Marinov et al. 2008). This process also plays a significant role in controlling the concentration of $\mathrm{CO}_{2}$ in the atmosphere (Sarmiento and Toggweiler 1984; Kwon et al. 2009).

Despite its importance, our present understanding of the biological pump is limited. This is largely due to the experimental and logistical challenges of quantifying particle fluxes in such a dynamic and inaccessible ecosystem. For the past several decades, various forms of conventional sediment traps have been deployed in subsurface waters, enabling the direct collection of sinking particulate material (Knauer and Asper 1989). Studies employing these techniques have revealed a wide dynamic range of flux magnitudes and attenuation length scales that exists throughout the oceans (Berelson 2001; Lutz et al. 2002; Buesseler et al. 2007b). Given that only modest changes to the global average flux attenuation length scale can have significant effects on atmospheric $\mathrm{CO}_{2}$ concentrations (Kwon et al. 2009), it is imperative that we aggressively quantify sinking particle fluxes in time and space to better understand their role in earth's biogeochemical dynamics 
and climate. However, in addition to being difficult and timeconsuming to deploy, sediment traps also tend to yield only a few data points, making them poorly suited for widespread oceanographic application and incapable of capturing the full range of spatial and temporal variations in particle fluxes that exists throughout the oceans. Therefore new strategies, technologies, sampling methods, and data analysis techniques are required to gain further insight into these dynamic processes.

Fortunately, the oceanographic toolbox for studying particle fluxes is expanding. Measurements of the particle reactive tracer ${ }^{234} \mathrm{Th}$ and recent advancements in its sampling methods and data interpretation are enabling higher resolution estimates of export fluxes and even provide some insight into particle remineralization immediately below the euphotic zone (Benitez-Nelson et al. 2001; Buesseler et al. 2009; Maiti et al. 2010). Autonomous floats have also become a capable platform for remote observations of carbon biomass and export (Bishop et al. 2004; Bishop 2009; Bishop and Wood 2009). With the development of improved digital photography, image processing capabilities, and oceanographic instrument design, in situ imaging of particles is emerging as a new and important tool in the study of particle concentrations and size distributions in the water column (Stemmann et al. 2004b; McDonnell and Buesseler 2010; Picheral et al. 2010). These instruments are capable of quickly and easily making observations of marine particles at high spatial and temporal resolutions, providing new opportunities for methodological developments and observation-based insights into marine particle dynamics and the ocean's biological pump.

In an important and novel study, Guidi et al. (2008) developed a global relationship between the particle concentration size distribution $\left(c_{n}\right)$ and measurements of bulk fluxes obtained with sediment traps. They described the total carbon flux $\left(F_{\mathrm{C}^{\prime}}\right.$ mmol $\mathrm{C} \mathrm{m}^{-2} \mathrm{~d}^{-1}$ ) as an integral over all particle diameters, $d$ :

$$
F_{\mathrm{C}}=\int c_{n}(d) m(d) w_{\text {avg }}(d) \mathrm{d} d
$$

where $c_{n}\left(\right.$ No. $\left.\mathrm{m}^{-3} \mu \mathrm{m}^{-1}\right)$ is the number concentration of particles in a given small size range $\mathrm{d} d, m(\mathrm{mmol} \mathrm{C})$ is the particle carbon content, and $w_{\text {avg }}\left(\mathrm{m} \mathrm{d}^{-1}\right)$ is the average sinking velocity of the particles, each as a function of $d$. Without explicit measurements of $m$ and $w_{\text {avg }}$ Guidi et al. (2008) used a single power law relationship for their product

$$
m \cdot w_{\text {avg }}=A \cdot d^{b}
$$

and empirically determined $A$ and $b$ by finding the best-fit parameters that most accurately predicted the bulk flux from measurements of $c_{n}$ made with an in situ camera system. This approach, however, relies on certain assumptions about the relationship between $c_{n}$ and the sinking flux. Furthermore, with its global scope, it cannot account for spatial or temporal variations in sinking velocity or carbon content with respect to location, depth, or time.
Although few measurements of sinking velocity exist for the open ocean, it is clear that sinking velocities are highly variable and can range over several orders of magnitude, depending on location, depth, time, or particle type (Turner 2002; Stemmann et al. 2004b; Armstrong et al. 2009; McDonnell and Buesseler 2010). This variability is significant even within regional and seasonal scales, suggesting that a single global relationship is likely not appropriate for the accurate estimation of flux from $c_{n}$ at any particular site or time (McDonnell and Buesseler 2010; Jouandet et al. 2011). In fact, several studies that employed the Guidi et al. (2008) global parameterization of $m \cdot w_{\text {avg }}$ found that estimated carbon fluxes were up to a factor of ten different from those measured by sediment traps at their sites (Iversen et al. 2010; Jouandet et al. 2011). Additionally, unless all particle imaging devices used in such studies are meticulously intercalibrated to give equivalent results for $c_{n}$ (Jackson et al. 1997; Picheral et al. 2010), the use of a single global parameterization for the calculation of particle flux will lead to biases that arise from inter-instrument variation in particle detection and differences in the image analysis algorithms used to calculate $c_{n}$.

To improve the local accuracy of the approach developed by Guidi et al. (2008), Iversen et al. (2010) applied the same minimization procedure using a small set of carbon flux and $c_{n}$ data pairs from Cape Blanc. Their study resulted in a different set of best-fit parameters, $A$ and $b$, from those determined from the global dataset of Guidi et al. (2008). This regional approach greatly improved the accuracy of flux estimates at this site. However, even in this regional context, the method still requires a single parameterization of $m \cdot w_{\text {avg }}$ to be applied over the entire range of locations, depths, or times used in the optimization procedure. In this manner, these methods have no mechanism to deal with variability of sinking velocity within the study area and also impose a single power law model for the product between $m$ and $w_{\text {avg }}$

Many types of direct measurements of particle sinking velocities are not appropriate for converting particle concentrations into fluxes because they often consider only the sinking fraction of particulate matter in the water column, and have no way to account for the often abundant suspended particulate matter that affects particle concentrations but not the sinking flux (Karl et al. 1988). One approach first applied by Bishop et al. (1986) is to identify and size individual particles in the water column and apply an empirical settling model for each type and size of particle to obtain estimates of sinking carbon. Bishop et al. (1986) used this method for several different morphological categories of identifiable fecal particles collected meticulously from in situ pumps. Recent studies that directly relate the flux size distribution $\left(F_{n}\right)$ to the associated $c_{n}$ (McDonnell and Buesseler 2010; Jouandet et al. 2011) result in measurements of the average sinking velocity distribution $\left(w_{\text {avg }}\right)$ as a function of particle size. Importantly, these studies found that $w_{\text {avg }}$ does not always follow a simple power law relationship with respect to particle size, making 
calculations of sinking velocity from a single formulation of Stokes' Law ineffective at accurately representing the relationship between the collection of particles in the water column and the $F_{n}$ that results from those particles. The $w_{\text {avg }}$ are the only type of sinking velocities that are appropriate for estimating the flux from the $c_{n}$ because they account for both the sinking and suspended particles and because they do not impose a power law type functionality with respect to size. Moreover, when $w_{\text {avg }}$ is computed from the ratio of the measured $F_{n}$ and $c_{n}$, this method can negate any errors in flux estimation that might arise from the common problem of the systematic under detection small particles as imaged by in situ camera systems (Jackson et al. 1997). This topic will be discussed in further detail below.

Experimental determinations of particle carbon contents are even more rare and difficult to obtain than sinking velocity. The small size and extremely fragile nature of these particles makes their physical sampling and processing a notoriously difficult task. The hand-collection of aggregates from surface waters by SCUBA divers has been the primary approach to address this difficult challenge (Alldredge and Gotschalk 1988; Alldredge 1998). However, this method produces uncertainties of up to an order of magnitude, requires immense sampling and laboratory efforts, and is restricted to typical SCUBA depths, thereby precluding its use throughout the mesopelagic and deep ocean waters. These challenges and the associated dearth of particle carbon content information add significant uncertainty to the estimation of particle fluxes from $F_{n}$ (Ebersbach and Trull 2008).

Whereas the pioneering approach of Guidi et al. (2008) shows promise for improving our measurement and understanding of the biological pump, the accuracy and portability of this global method to different ocean ecosystems remains a major limitation. What is needed for the improvement of flux estimations from in situ camera derived measurements of $c_{n}$ is a method that captures the regional and temporal variability of particle sinking velocities and particle carbon content.

Here we address these challenges by describing a new method for the estimation of carbon flux that relies on independent and local determinations of average sinking velocities and carbon content as functions of particle size. These locally calibrated relationships allow for the improved accuracy in the estimation of particle flux from the $c_{n}$ and facilitate a dramatic enhancement in the spatial and temporal coverage of flux measurements well beyond what is possible with conventional sediment traps alone. Furthermore, the local quantification of $w_{\text {avg }}$ and particle carbon content can provide new insights into the mechanisms that control the strength and efficiency of the ocean's biological pump.

\section{Materials and procedures}

\section{Measurement of reference fluxes}

Particle flux was measured directly with two different types of sediment traps: 1) bulk flux collectors and 2) polyacry- lamide gel traps. Both traps were of identical cylindrical geometries $(12 \mathrm{~cm}$ aperture and a height of $70 \mathrm{~cm}$ ), and made of extruded acrylic tubing with shallow PVC cones serving as base caps. The tubes had cylindrical baffles (1 cm diameter) and PVC lids secured with elastic bungee to facilitate automatic closure of the tubes at the end of the collection phase of the deployment (Lamborg et al. 2008). The traps were deployed from a single drifting sediment trap array consisting of a primary surface float, and a subsurface bungee and float to minimize the hydrodynamic effect of surface wave action on the collection devices at depth (Fig. 1). Traps were attached to aluminum frames at three discrete collection depths: 200, 300 , and $500 \mathrm{~m}$ below the surface. These depths were chosen because they are immediately below the base of the euphotic zone at our study site (described below) and therefore in the depth range where the magnitude of flux attenuation is at a maximum (Buesseler and Boyd 2009). The collection phases lasted approximately $1.5 \mathrm{~d}$ (Table 1 ), after which pre-programmed underwater controllers closed the lids on the traps with release pins or burn wires. The drifting array was recovered aboard the ship within $24 \mathrm{~h}$ of the lid closure.

The first type of sediment trap consisted of a standard cylindrical tube serving as a bulk flux collector. The bulk flux collectors intercept sinking particulate matter and allow it to accumulate in the bottom of the collection tube in the shallow cone of the PVC base plate. Before deployment, the trap tubes were rinsed three times with deionized water and then another three times with filtered (1- $\mu$ m Hytrex cartridge) seawater from $150 \mathrm{~m}$ depth at the trap site. The tubes were then filled with the 1- $\mu \mathrm{m}$ filtered seawater up to $10 \mathrm{~cm}$ below the top of the collection tube. A funnel with a valve and narrow tube equal to the length of the sediment trap was used to add $500 \mathrm{~mL}$ formalin-poisoned and filtered brine (salinity $70 \mathrm{psu}$ ) to the base of the trap. This brine was prepared by filtering seawater through the 1- $\mu \mathrm{m}$ cartridge filter, freezing it in a large carboy, and then collecting the high-salinity melt fraction of the water until the salinity reached approximately $70 \mathrm{psu}$ as measured with a refractometer. The brine was then buffered by adding $20 \mathrm{~mL}$ of $150 \mathrm{mM}$ boric acid $(\mathrm{pH}=8)$ per liter of brine. Formalin (37\%) was added to reach a final concentration of $0.022 \%$, and the solution was refiltered with a 1- $\mu$ m Hytrex cartridge. The high density of this brine solution keeps the poison in the base of the trap where settling particles collect, thereby preventing biological breakdown of the particulate matter by bacteria and zooplankton.

After the collection phase, the traps were recovered aboard the ship and the particulate matter was allowed to settle for 1 $\mathrm{h}$ before the seawater overlying the brine was siphoned off. The brine and particle sample mixture was then drained through a $350-\mu \mathrm{m}$ Nitex screen to remove swimmers. Studies at the BATS site showed that there was no difference in removal of swimmers using this screening method versus individual removal of swimmers under a microscope (S. Owens pers. comm.). The screened brine suspension was filtered through a $1.2-\mu \mathrm{m}$ silver 


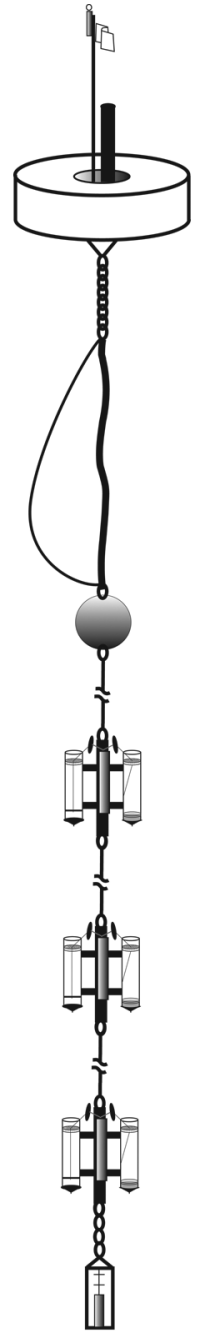

Fig. 1. Schematic of the drifting sediment trap array used in this study. The drifter consists of a surface float with an ARGOS beacon, fiberglass mast, LED strobe, and flag. Not pictured is a small secondary float connected to the main float with $10 \mathrm{~m}$ tag line that aids in the recovery of the array. Beneath the waterline, stainless steel chain is connected to a heavyduty elastic bungee with a parallel safety line followed by a subsurface float which acts to dampen the effects of surface waves on the sediment traps below. Sediment trap frames were deployed at 3 depths (200, 300, and $500 \mathrm{~m}$ ) and separated by a braided and jacketed Vectran chord (diameter of 0.375 inches). Bulk flux-collecting traps and polyacrylamide gel traps were attached to each trap frame along with a CLAP trap controller outfitted with burn wires to facilitate the closure of the trap lids at the end of the flux collection period. An acoustic current meter was attached to the bottom of the drifting array to monitor relative current sheer.

membrane filter (Sterlitech), and the particles dried for $\sim 24 \mathrm{~h}$ at $50^{\circ} \mathrm{C}$. The filtered samples were analyzed on a $\mathrm{CHN}$ analyzer to determine the quantity of carbon collected in the sediment trap. Carbon flux, $F_{\mathrm{C}}^{\text {trap }}$, was calculated by dividing this value by the duration of the collection period and the cross-sectional collection area of the cylindrical traps.

The flux size distribution, $F_{n}$, was determined through the use of a second trap type, a polyacrylamide gel trap as described in detail in McDonnell and Buesseler (2010), and used in several previous studies of particle flux (Lundsgaard 1995; Waite and Nodder 2001; Ebersbach and Trull 2008). These devices were deployed on the same drifting array and immediately adjacent to the bulk flux collectors on the trap frames. Details of the polyacrylamide gel preparation, sample handling, imaging workflow, and image analysis are identical to those described in McDonnell and Buesseler (2010).

The imaged particles were then classified into predefined and logarithmically spaced size classes (specified in Tables 3, 4, and 5) according to their equivalent spherical diameters, $d$. In each size class, the numerical flux was then normalized to the width of each size bin, resulting in gel-derived measurements of the flux size distribution, $F_{n}^{\text {gel }}$ (No. $\mathrm{m}^{-2} \mathrm{~d}^{-1} \mu \mathrm{m}^{-1}$ ).

Measurement of the particle concentration size distribution

The concentrations of particles in the water column were measured with the autonomous video plankton recorder (VPR), an underwater digital microscope system manufactured by Seascan. The VPR takes still images of particles in an undisturbed parcel of water located between the camera housing and strobe illuminator as the instrument is lowered and raised independently through the water column on a nonconducting wire at approximately $30 \mathrm{~m} \mathrm{~min}^{-1}$. A full description of the instrument can be found in Davis et al. (1996) and the methodology and MATLAB code for analyzing the images and calibrating the instrument is described in detail in McDonnell and Buesseler (2010) and documented in McDonnell (2011). We conducted two vertical profiles from the surface down to a maximum of $600 \mathrm{~m}$ at each location and used every second image (to avoid overlapping frames) from both the up-casts and the down-casts. The deployment configuration was such that the image volume was located off the center axis of the instrument, and in a location without turbulent effects of the instrument wake during either the up- or downcasts. Both the up- and downcasts resulted in nearly identical $c_{n}$, so we combined them to increase the sampling density and therefore reduce the uncertainty in $c_{n}$.

The concentration size distribution, $c_{n}\left(\right.$ No. $\left.\mathrm{m}^{-3} \mu \mathrm{m}^{-1}\right)$, was calculated by dividing the number of particle counts for each size bin by the total imaged volume and the width of the given size bin $d$. The total imaged volume was calculated by multiplying the number of images analyzed in that $50 \mathrm{~m}$ depth range by the image volume of each VPR photograph $(61.7 \mathrm{~mL})$. Under typical deployment configurations, the total imaged volume for each $50 \mathrm{~m}$ depth bin is approximately 150 L. The sizes of the depth intervals and particle size bins were chosen somewhat arbitrarily to balance the competing concerns of high resolution with respect to depth and particle size versus the uncertainties that arise in $c_{n}$ from a small number of particle counts in increasingly higher-resolution bins. Uncertainty in the observed $c_{n}$ was of particular concern for the largest particles in the size range sampled by the VPR because 
Table 1. List of parameters used in this method, their descriptions, and units. "No." refers to the number of particles; $d$ is the length of time in days. All other units are standard SI units.

\begin{tabular}{|c|c|c|}
\hline Symbol & Description & Units \\
\hline$F_{n}$ & Numerical sinking flux size distribution & No. $\mathrm{m}^{-2} \mathrm{~d}^{-1} \mu \mathrm{m}^{-1}$ \\
\hline$F_{n}^{\text {calc }}$ & Numerical sinking flux size distribution calculated from the measured $c_{n}$ and $w_{\text {avg }}$ & No. $\mathrm{m}^{-2} \mathrm{~d}^{-1} \mu \mathrm{m}^{-1}$ \\
\hline$F_{n}^{\text {gel }}$ & Numerical sinking flux size distribution derived from the polyacrylamide gel traps & No. $\mathrm{m}^{-2} \mathrm{~d}^{-1} \mu \mathrm{m}^{-1}$ \\
\hline$c_{n}$ & Numerical concentration size distribution & No. $\mathrm{m}^{-3} \mu \mathrm{m}^{-1}$ \\
\hline$w_{\text {avg }}$ & Average sinking velocity size distribution & $\mathrm{m} \mathrm{d}^{-1}$ \\
\hline$m$ & particle carbon content & $\mathrm{mmol} \mathrm{C}$ \\
\hline$d$ & Equivalent spherical diameter & $\mu \mathrm{m}$ \\
\hline$F_{\mathrm{C}}^{\text {est }}$ & Sinking carbon flux, estimated by the method presented here & 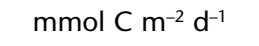 \\
\hline$F_{\mathrm{C}}^{\text {trap }}$ & Sinking carbon flux, as measured by the sediment trap & $\mathrm{mmol} \mathrm{C} \mathrm{m} \mathrm{m}^{-2} \mathrm{~d}^{-1}$ \\
\hline$\Delta F_{\mathrm{C}}$ & Sum of the squared differences between sediment trap flux and the estimated flux & $\mathrm{mmol} \mathrm{C} \mathrm{m}^{-4} \mathrm{~d}^{-2}$ \\
\hline$\alpha$ & Best-fit constant for the relationship between $F_{n}^{\text {gel }}$ and $F_{\mathrm{C}}^{\text {trap }}$ & $\mathrm{mmol} C \mu \mathrm{m}^{-\beta}$ \\
\hline$\beta$ & Best-fit exponent for the relationship between $F_{n}^{\text {gel }}$ and $F_{\mathrm{C}}^{\text {trap }}$ & - \\
\hline$A$ & Best-fit constant for the Guidi et al. (2008) relationship between $F_{\mathrm{C}}$ and $c_{n}$ & $\mathrm{mmol} \mathrm{C} \mathrm{m} \mathrm{d}^{-1} \mu \mathrm{m}^{-b^{\star}}$ \\
\hline$b$ & Best-fit exponent for the Guidi et al. (2008) relationship between $F_{\mathrm{C}}$ and $c_{n}$ & - \\
\hline
\end{tabular}

"Note that Guidi et al. (2008) and Iversen et al. (2010) report $A$ in the units of $\mathrm{mg} \mathrm{L} \mathrm{mm}^{-b} \mathrm{~m}^{-2} \mathrm{~d}^{-1}$. Their reported constants were converted to the units

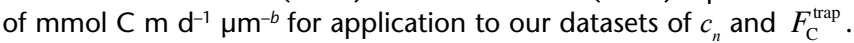

they are so rare that they needed to be grouped into increasingly larger size bins (hence the logarithmic bin spacing) and a large volume of water needed to be sampled (this was accomplished by using $50 \mathrm{~m}$ depth bins).

We define two different types of oceanographic stations based on their different purposes: reference sites and proxy sites. Reference sites are stations used for the calibration of the average sinking velocity size distribution and particle carbon content and consisted of VPR profiles conducted within $1 \mathrm{~km}$ of the drifting sediment traps during the trap collection phase. This strict spatial and temporal proximity ensures that measurements of the particle flux and concentration are representative of the same particle populations, thereby enabling proper calibration. Proxy sites are stations where there are no direct measurements of particle flux from sediment traps. Instead, the VPR is deployed at proxy sites for the purpose of estimating the particle flux from $c_{n}$.

Calculation of the average sinking velocity size distribution

The average sinking velocity, $w_{\text {avg }}\left(\mathrm{m} \mathrm{d}^{-1}\right)$ for each size class, $d_{i}$, is calculated by the equation

$$
w_{\text {avg }}\left(d_{i}\right)=F_{n}^{\mathrm{gel}}\left(d_{i}\right) \cdot c_{n}\left(d_{i}\right)^{-1}
$$

where $F_{n}^{\text {gel }}\left(\right.$ No. $\left.\mathrm{m}^{-2} \mathrm{~d}^{-1} \mu \mathrm{m}^{-1}\right)$ is the measured numeric flux and $c_{n}\left(\right.$ No. $\left.\mathrm{m}^{-3} \mu \mathrm{m}^{-1}\right)$ is the VPR-measured particle concentration size distribution as described above.

\section{Calculation of the particle carbon content}

To calculate an estimate of the carbon flux $F_{\mathrm{C}}^{\mathrm{est}} \quad$ (mmol C $\mathrm{m}^{-2} \mathrm{~d}^{-1}$ ) from the numeric particulate flux, $F_{n}$, a relationship for the particle carbon content is necessary. Here we use a power law formulation of carbon content as a function of particle diameter $(d, \mu \mathrm{m})$ equivalent to that used by Alldredge and Gotschalk (1988) and Alldredge (1998):

$$
F_{\mathrm{C}}^{\mathrm{est}}=\sum\left[F_{n}\left(d_{i}\right) \cdot \alpha \cdot d_{i}^{\beta} \cdot \Delta d_{i}\right]
$$

where $\Delta d_{i}$ is the width $(\mu \mathrm{m})$ of each size bin $i$. To determine the parameters $\alpha$ and $\beta$, we directly compare the measurements of $F_{n}^{\text {gel }}$ to the bulk carbon flux collected in side-byside sediment traps. In a manner similar to that of Guidi et al. (2008), this is accomplished with the MATLAB function "fminsearch" to optimize $\alpha$ and $\beta$ by minimizing the logtransformed differences $\left(\Delta F_{\mathrm{C}}\right)$ between the estimated carbon flux, $F_{\mathrm{C}}^{\text {est }}$, derived from Eq. 4 and the measured bulk carbon trap flux $\left(F_{\mathrm{C}}^{\text {trap }}\right)$ :

$$
\Delta F_{\mathrm{C}}=\sum\left(\log \left(F_{\mathrm{C}}^{\text {trap }}\right)-\log \left(F_{\mathrm{C}}^{\text {est }}\right)\right)^{2}
$$

Calculation of carbon flux from the concentration size distribution

After obtaining local calibrations of $w_{\text {avg }}$ and the particle carbon content parameters at the reference site(s), it is then possible to accomplish the ultimate goal of this method, which is to estimate the magnitude of the carbon flux from independent measurements of concentration size distribution, $c_{n}$.

The VPR yields high-resolution measurements of $c_{n}$ at the flux proxy sites. The numeric flux size distribution, $F_{n}^{\text {calc }}$, is then calculated from the product of the measured particle concentrations and the average sinking velocities for each size class:

$$
F_{n}^{\mathrm{calc}}=c_{n} \cdot w_{\mathrm{avg}}
$$

Because $w_{\text {avg }}$ varies with respect to location, depth, and time (McDonnell and Buesseler 2010), it becomes important to include this variability when estimating the flux. Thus, the appropriate $w_{\text {avg }}$ used in Eq. 6 was the most proximal value available in these dimensions. Once $F_{n}^{\text {calc }}$ has been calculated 
from $c_{n}$ and $w_{\text {avg }}$ Eq. 4 is used to calculate the carbon flux at the proxy sites.

\section{Assessment}

To evaluate and demonstrate the utility of this method, several experiments were conducted in 2009 during cruises in the region of the Bermuda Atlantic Time-Series (BATS) site approximately $75 \mathrm{~km}$ to the southeast of Bermuda in the subtropical Sargasso Sea. This site has a long and rich history of oceanographic research, including multiple studies of sinking particle fluxes that have provided critical insights into the function of the ocean's biological pump (Deuser and Ross 1980; Deuser et al. 1981; Conte et al. 2001). An overview of this site and its physical, biological, and biogeochemical attributes can be found in Steinberg et al. (2001).

We deployed the drifting sediment trap array three times, the details of which are shown in Table 2. These deployments served as the reference sites from which calibrations of the $w_{\text {avg }}$ and particle carbon content were obtained.

The flux collected in the polyacrylamide gels was numerically dominated by small $(25<d<100 \mu \mathrm{m})$, light colored, and nearly spherical particles (Fig. 2). Less common (but still significant in terms of their projected areas) were larger particles up to about $1 \mathrm{~mm}$ in diameter (Fig. 2). The flux material appeared to be quite heterogeneous, likely reflecting the diverse community of phytoplankton and zooplankton that are the source for sinking particles in the subtropical ocean (Brew et al. 2009; Wilson and Steinberg 2010; Lomas and Moran 2011). Analyses of the gel images allowed for the quantification of the flux size distribution, $F_{n}^{\text {gel }}$, for each sample, and these results are presented in Table 3 . The numeric flux decreased for increasing particle size, and generally decreased with depth in a given size bin as well. The relative standard deviation between the three reference deployments at identical depths and size classes averaged about 30\%, indicating temporal variability in $F_{n}^{\text {gel }}$ between deployments.
Image analysis of the VPR casts conducted at these reference sites produced the concentration size distributions, $c_{n}$, of Table 4 . The smallest particles observed were about 6 orders of magnitude more abundant than those in the larger size classes. Particles of $d>1 \mathrm{~mm}$ were rare; even with hundreds of images in each depth bin, very few of these large particles were observed, leading to large uncertainties in their actual concentration. The magnitudes of $c_{n}$ decreased with increasing depth beneath the euphotic zone. There was also variability between the three different sampling dates, with $c_{n}$ exhibiting an average relative standard deviation of 35\% among identical depth and size bins, similar to the variability observed in $F_{n}^{\text {gel }}$.

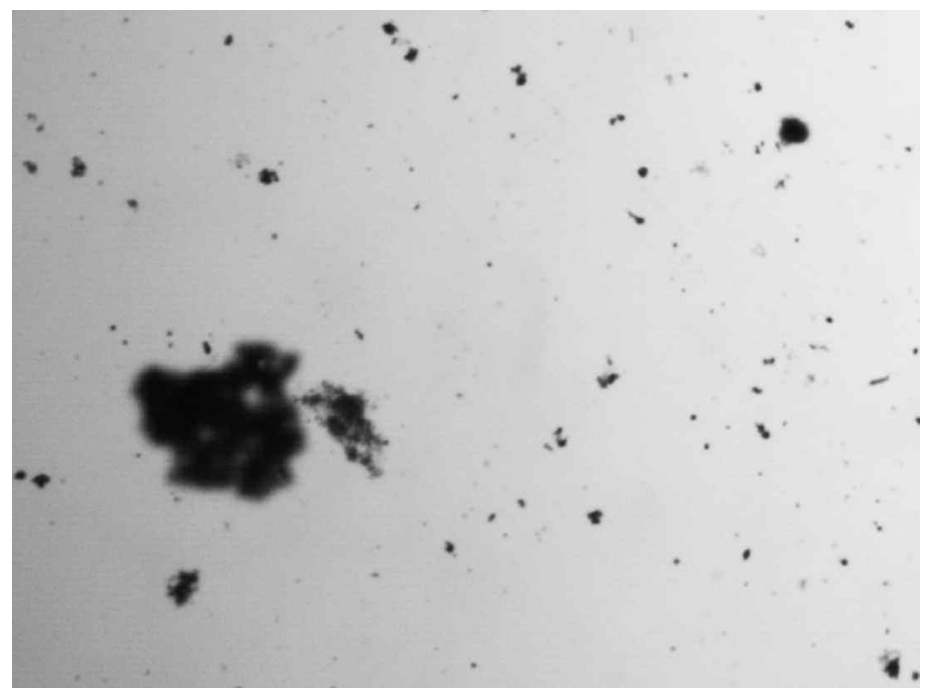

Fig. 2. Microscopic photographs of $0.5 \mathrm{~cm}$ wide section of a polyacrylamide gel trap deployed at the BATS site. This image is from a gel deployed on 15 May 2009 at $200 \mathrm{~m}$ depth. The image gives an example of the distribution of particles that make up the sinking flux. Large particles, such as the one featured here, were very rare but included here as an example of the range of particle sizes observed at this location.

Table 2. Description of the drifting trap deployments used as flux reference sites in the Sargasso Sea during 2009 . The availability of the different data types is noted in the last three columns.

\begin{tabular}{|c|c|c|c|c|c|c|c|}
\hline $\begin{array}{l}\text { Drifter deployment } \\
\text { date and time (local) }\end{array}$ & $\begin{array}{c}\text { Drifter } \\
\text { deployment } \\
\text { location }\end{array}$ & $\begin{array}{l}\text { Drifter } \\
\text { recovery } \\
\text { location }\end{array}$ & $\begin{array}{c}\text { Collection } \\
\text { duration } \\
\text { (days) }\end{array}$ & $\begin{array}{l}\text { Trap } \\
\text { depths } \\
\text { (m) }\end{array}$ & $\begin{array}{c}\text { Trap } \\
\text { carbon flux } \\
\text { measurement }\end{array}$ & Gel trap & VPR profile \\
\hline 15 May 2009 & $31^{\circ} 35.02^{\prime} \mathrm{N}$ & $31^{\circ} 45.96^{\prime} \mathrm{N}$ & 1.46 & 200 & no & yes & yes \\
\hline \multirow[t]{2}{*}{ 03:18 } & $64^{\circ} 09.60^{\prime} \mathrm{W}$ & $64^{\circ} 22.03^{\prime} \mathrm{W}$ & & 300 & no & yes & yes \\
\hline & & & & 500 & no & yes & yes \\
\hline 14 Jul 2009 & $31^{\circ} 32.91^{\prime} \mathrm{N}$ & $31^{\circ} 21.06^{\prime} \mathrm{N}$ & 1.52 & 200 & yes & yes & yes \\
\hline \multirow[t]{2}{*}{ 03:14 } & $64^{\circ} 09.94^{\prime} \mathrm{W}$ & $64^{\circ} 12.18^{\prime} \mathrm{W}$ & & 300 & yes & yes & yes \\
\hline & & & & 500 & yes & no* & yes \\
\hline 21 Sep 2009 & $31^{\circ} 34.93^{\prime} \mathrm{N}$ & $31^{\circ} 14.80^{\prime} \mathrm{N}$ & 1.48 & 200 & yes & yes & yes \\
\hline \multirow[t]{2}{*}{$09: 23$} & $64^{\circ} 09.97^{\prime} \mathrm{W}$ & $63^{\circ} 35.90^{\prime} \mathrm{W}$ & & 300 & yes & yes & yes \\
\hline & & & & 500 & yes & yes & yes \\
\hline
\end{tabular}

*A gel trap was deployed at this location but the lid closure mechanism failed, preventing the measurement of $F_{n}^{\text {gel }}$. 
Table 3. The flux size distribution, $F_{n}^{\text {gel }}$, measured from deployments of the polyacrylamide gel traps deployed in the Sargasso Sea in 2009. Particle fluxes are binned according to their equivalent spherical diameters listed in the table.

\begin{tabular}{|c|c|c|c|c|c|c|c|c|c|c|}
\hline \multirow[t]{2}{*}{$\begin{array}{l}\text { Deployment } \\
\text { dates (2009) }\end{array}$} & \multirow[t]{2}{*}{ Depth (m) } & \multicolumn{9}{|c|}{ Number flux, $F_{n}^{\text {gel }}\left(\right.$ No. $\left.\mathbf{m}^{-2} \mathbf{d}^{-1} \mu_{\mathbf{m}^{-1}}\right)$} \\
\hline & & $73-120$ & $120-195$ & $195-320$ & $320-520$ & $520-850$ & $850-1400$ & $1400-2290$ & $2290-3740$ & $3740-6110$ \\
\hline & & $\mu \mathrm{m}$ & $\mu \mathrm{m}$ & $\mu \mathrm{m}$ & $\mu \mathrm{m}$ & $\mu \mathrm{m}$ & $\mu \mathrm{m}$ & $\mu \mathrm{m}$ & $\mu \mathrm{m}$ & $\mu \mathrm{m}$ \\
\hline \multirow[t]{3}{*}{15 May } & 200 & 15500 & 3370 & 482 & 54.9 & 7.03 & 0.717 & - & - & - \\
\hline & 300 & 12500 & 2990 & 531 & 65.7 & 2.80 & - & - & - & - \\
\hline & 500 & 9660 & 1830 & 364 & 56.8 & 5.02 & 0.708 & - & - & - \\
\hline \multirow[t]{3}{*}{$14 \mathrm{Jul}$} & 200 & 19300 & 2970 & 514 & 140. & 23.5 & 3.85 & - & - & - \\
\hline & 300 & 14600 & 2120 & 445 & 106 & 9.70 & 0.204 & - & - & - \\
\hline & 500 & * & * & * & * & * & * & * & * & * \\
\hline \multirow[t]{3}{*}{$21 \mathrm{Sep}$} & 200 & 23600 & 3120 & 608 & 127 & 8.63 & 1.17 & - & - & - \\
\hline & 300 & 26400 & 3300 & 481 & 103 & 9.54 & 0.188 & 0.115 & - & - \\
\hline & 500 & 30100 & 2480 & 281 & 43 & 5.81 & 0.748 & - & - & - \\
\hline
\end{tabular}

—, no particles detected in the gel for that given size class; ${ }^{*}$ Failed closure of a polyacrylamide gel trap

Table 4. The numeric particle concentration size distributions $\left(c_{n}\right)$ measured by the VPR for the three reference deployments in 2009. The values are binned according to the specified equivalent spherical diameter size bins $\left(d_{i}\right)$ and $50 \mathrm{~m}$ depth bins immediately above the depths listed in the second column. Dashes indicate that there were no particles of that size class detected by the VPR.

\begin{tabular}{|c|c|c|c|c|c|c|c|c|c|c|}
\hline \multirow[t]{2}{*}{$\begin{array}{l}\text { Deployment } \\
\text { dates (2009) }\end{array}$} & \multirow[t]{2}{*}{ Depth (m) } & \multicolumn{9}{|c|}{ Number concentration, $c_{n}\left(\right.$ No. $\left.\mathrm{m}^{-3} \mu \mathrm{m}^{-1}\right)$} \\
\hline & & $\begin{array}{c}73-120 \\
\mu \mathrm{m}\end{array}$ & $\begin{array}{c}120-195 \\
\mu \mathrm{m}\end{array}$ & $\begin{array}{c}195-320 \\
\mu \mathrm{m}\end{array}$ & $\begin{array}{c}320-520 \\
\mu \mathrm{m}\end{array}$ & $\begin{array}{c}520-850 \\
\mu \mathrm{m}\end{array}$ & $\begin{array}{c}\text { 850-1400 } \\
\mu \mathrm{m}\end{array}$ & $\begin{array}{c}1400-2290 \\
\mu \mathrm{m}\end{array}$ & $\begin{array}{c}2290-3740 \\
\mu \mathrm{m}\end{array}$ & $\begin{array}{c}3740-6110 \\
\mu \mathrm{m}\end{array}$ \\
\hline \multirow[t]{3}{*}{15 May } & 200 & 1591 & 381.5 & 68.6 & 10.5 & 1.37 & 0.105 & 0.00917 & 0.00343 & - \\
\hline & 300 & 972 & 267 & 53.4 & 8.59 & 1.12 & 0.102 & 0.00889 & - & - \\
\hline & 500 & 330 & 93.2 & 22.8 & 5.13 & 0.429 & 0.0552 & - & - & - \\
\hline \multirow[t]{3}{*}{$14 \mathrm{Jul}$} & 200 & 1230 & 386 & 88.5 & 13.7 & 1.60 & 0.132 & 0.00476 & - & - \\
\hline & 300 & 770 & 243 & 57.5 & 10.6 & 1.22 & 0.0697 & 0.00474 & - & - \\
\hline & 500 & 567 & 157 & 36.0 & 6.07 & 0.760 & 0.087 & 0.00482 & & \\
\hline \multirow[t]{3}{*}{$21 \mathrm{Sep}$} & 200 & 654 & 193 & 41.5 & 7.47 & 1.46 & 0.0670 & 0.0137 & 0.00835 & - \\
\hline & 300 & 581 & 142 & 27.3 & 4.72 & 0.721 & 0.0163 & - & - & 0.00374 \\
\hline & 500 & 556 & 153 & 29.3 & 3.16 & 0.357 & 0.0297 & - & 0.00371 & 0.00453 \\
\hline
\end{tabular}

The simple division of $F_{n}^{\text {gel }}$ (Table 3) by $c_{n}$ (Table 4) allowed for the calculation of the average sinking velocity size distribution $w_{\text {avg }}$ (Table 5) at the times and locations of each polyacrylamide gel trap. We found $w_{\text {avg }}$ that ranged from $2-54 \mathrm{~m}$ $\mathrm{d}^{-1}$. Each deployment and depth yielded slightly different $w_{\text {avg }}$ magnitudes and size distributions, indicating some variability in the average sinking velocity of the particles present in the water column. However, these variations were small compared with those we observed along the western Antarctic Peninsula where $w_{\text {avg }}$ ranged from $10-250 \mathrm{~m} \mathrm{~d}^{-1}$ depending on particle size, trap depth, location, and time of year (McDonnell and Buesseler 2010). Although there were no distinct and persistent trends in $w_{\text {avg }}$ in several cases the smaller size classes did have slightly faster velocities than the mid-sized and largest particles. Particularly in the small size classes, sinking velocity tended to increase slightly as a function of depth, a change primarily driven by declining $c_{n}$ with respect to depth while $F_{n}^{\text {gel }}$ changed very little from the shallow to the deep in these small size classes.

The next step in this method was to calculate the best-fit parameters for the power law representation of carbon content, $m$, as a function of $d$ at the reference stations. Unlike the calculations of $w_{\text {avg }}$ that can be accomplished at the locations and depths of each polyacrylamide gel trap, the parameterization of carbon content requires the comparison of $F_{n}^{\text {gel }}$ and bulk carbon flux from multiple pairs of polyacrylamide gel and standard sediment trap collection tubes. The minimization procedure results in a single set of best-fit parameters, $\alpha$ and $\beta$ that we apply across all of the reference sites used in the procedure. In this study, we used the five $F_{n}^{\text {gel }}$ and $F_{\mathrm{C}}^{\text {trap }}$ pairs that were available at BATS during these deployments. Because no $F_{\mathrm{C}}^{\text {trap }}$ data were available from the May deployment, only 
Table 5. Average sinking velocities, $w_{\text {avg }}$ computed by dividing the numeric fluxes in Table 3 by the numeric concentrations in Table 4. Dashes indicate that no particles of that size were collected in the gel.

\begin{tabular}{|c|c|c|c|c|c|c|c|c|c|c|}
\hline \multirow[t]{2}{*}{$\begin{array}{l}\text { Deployment } \\
\text { dates (2009) }\end{array}$} & \multirow[t]{2}{*}{ Depth (m) } & \multicolumn{9}{|c|}{ Average sinking velocity, $w_{\text {avg }}\left(\mathrm{m} \mathrm{d}^{-1}\right)$} \\
\hline & & $73-120$ & $120-195$ & $195-320$ & $320-520$ & $520-850$ & $850-1400$ & $1400-2290$ & $2290-3740$ & $3740-6110$ \\
\hline & & $\mu \mathrm{m}$ & $\mu \mathrm{m}$ & $\mu \mathrm{m}$ & $\mu \mathrm{m}$ & $\mu \mathrm{m}$ & $\mu \mathrm{m}$ & $\mu \mathrm{m}$ & $\mu \mathrm{m}$ & $\mu \mathrm{m}$ \\
\hline \multirow[t]{3}{*}{15 May } & 200 & 9.74 & 8.83 & 7.02 & 5.23 & 5.12 & 6.82 & - & - & $\ddagger$ \\
\hline & 300 & 12.9 & 11.2 & 9.96 & 7.65 & 2.51 & - & - & $¥$ & $\ddagger$ \\
\hline & 500 & 29.3 & 19.6 & 15.9 & 11.1 & 11.7 & 12.8 & $\ddagger$ & $\ddagger$ & $\ddagger$ \\
\hline \multirow[t]{3}{*}{$14 \mathrm{Jul}$} & 200 & 15.7 & 7.70 & 5.81 & 10.2 & 14.7 & 29.1 & - & $¥$ & $\ddagger$ \\
\hline & 300 & 19.0 & 8.72 & 7.75 & 10.1 & 7.97 & 2.93 & - & $\ddagger$ & $\ddagger$ \\
\hline & 500 & * & * & * & * & * & * & * & * & * \\
\hline \multirow[t]{3}{*}{$21 \mathrm{Sep}$} & 200 & 36.0 & 16.2 & 14.6 & 17.0 & 5.90 & 17.5 & - & - & $\ddagger$ \\
\hline & 300 & 45.5 & 23.2 & 17.6 & 21.9 & 13.2 & 11.5 & $\dagger$ & $\ddagger$ & - \\
\hline & 500 & 54.1 & 16.2 & 9.58 & 13.6 & 16.3 & 25.1 & $\ddagger$ & - & - \\
\hline
\end{tabular}

${ }^{*}$ Failed closure of the polyacrylamide gel trap deployed in Jul at $500 \mathrm{~m}$; ${ }^{\dagger}$ Particles collected in the flux, however none in that size class were detected in the water column $c_{n}$ measured by the VPR; ${ }^{\ddagger}$ No particles were detected in either the flux or the concentration.

Table 6. Carbon fluxes measured by the drifting sediment traps compared with three different methods for estimating the flux from $c_{n}$. All fluxes have the units of $\mathrm{mmol} \mathrm{C} \mathrm{m}^{-2} \mathrm{~d}^{-1}$.

\begin{tabular}{|c|c|c|c|c|c|c|}
\hline $\begin{array}{l}\text { Deployment } \\
\text { date (2009) }\end{array}$ & $\begin{array}{l}\text { Depth } \\
(\mathrm{m})\end{array}$ & $\begin{array}{c}\text { Measured carbon } \\
\text { flux from } \\
\text { sediment trap }\end{array}$ & $\begin{array}{l}\text { Estimated } \\
\text { carbon flux } \\
\text { (this study) }\end{array}$ & $\begin{array}{c}\text { Estimated } \\
\text { carbon flux } \\
\text { (Guidi et al. 2008) }\end{array}$ & $\begin{array}{c}\text { Estimated } \\
\text { carbon flux } \\
\text { (Iversen et al. } \\
\text { 2010) }\end{array}$ & $\begin{array}{c}\text { Estimated } \\
\text { carbon flux } \\
\text { (local fit by Iversen } \\
\text { et al. [2010] method) }\end{array}$ \\
\hline \multirow[t]{3}{*}{15 May } & 200 & * & 1.61 & 0.30 & 5.43 & 4.07 \\
\hline & 300 & * & 1.20 & 0.25 & 4.76 & 2.79 \\
\hline & 500 & * & 1.26 & 0.12 & 2.21 & 1.07 \\
\hline \multirow[t]{3}{*}{$14 \mathrm{Jul}$} & 200 & 4.09 & 3.55 & 0.36 & 6.58 & 3.98 \\
\hline & 300 & 2.50 & 1.67 & 0.25 & 4.42 & 2.59 \\
\hline & 500 & 1.84 & $\dagger$ & 0.19 & 3.57 & 1.73 \\
\hline \multirow[t]{3}{*}{21 Sep } & 200 & 2.07 & 2.33 & 0.24 & 4.45 & 2.11 \\
\hline & 300 & 1.79 & 1.93 & 0.11 & 1.88 & 1.57 \\
\hline & 500 & 1.30 & 1.47 & 0.082 & 1.46 & 1.54 \\
\hline
\end{tabular}

${ }^{*}$ No sediment trap carbon flux data available; ${ }^{\dagger}$ No gel trap data were available at this depth for the estimation of the average sinking velocity distribution.

the July and September fluxes were used (Table 6). The minimization procedure yielded the best-fit parameters of $\alpha=9.28$ $\times 10^{-14} \mathrm{mmol} \mathrm{C} \mu \mathrm{m}^{-\beta}$ and $\beta=3.24$. This single parameterization of $m$ was applied to all the flux estimates presented here (except for the cases in which this method is compared with other flux estimation methods). An identical procedure with data from the western Antarctic Peninsula yielded the best-fit parameters of $\alpha=3.91 \times 10^{-12} \mathrm{mmol} \mathrm{C} \mu \mathrm{m}^{-\beta}$ and $\beta=2.53$ (McDonnell 2011). This variability demonstrates the importance of a local/regional determination of carbon content rather than a more generalized global parameterization.

When these parameters are applied to the gel-derived measurements of $F_{n}^{\text {gel }}$, they successfully yield carbon flux estimates that are within a few tenths of a mmol $\mathrm{C} \mathrm{m}^{-2} \mathrm{~d}^{-1}$ of those measured by the bulk collectors (Fig. 3). This is not surprising, given that the procedure used to determine $\alpha$ and $\beta$ is designed to minimize these errors. It does give us confidence, however, that the power law formulation of particle carbon content is appropriate for this purpose.

The parameter $\alpha$ represents a carbon content parameter and $\beta$ describes how the carbon content scales with respect to the particle size. A value of $\beta=3.24$ is greater than the maximum value of 3 expected if the flux carbon content distribution varies in accordance with fractal theory of aggregate formation (Logan and Wilkinson 1990; Jackson and Burd 1998). This value suggests that the larger particles in the size range are actually more carbon rich than would be expected if formed of the same material as the smaller aggregates. Visual inspection of the gel images revealed that the largest sinking particles contained dark and likely very carbon-rich components, such as highly compacted zooplankton fecal matter (Fig. 2). Conversely, many of the smallest particles were lighter 


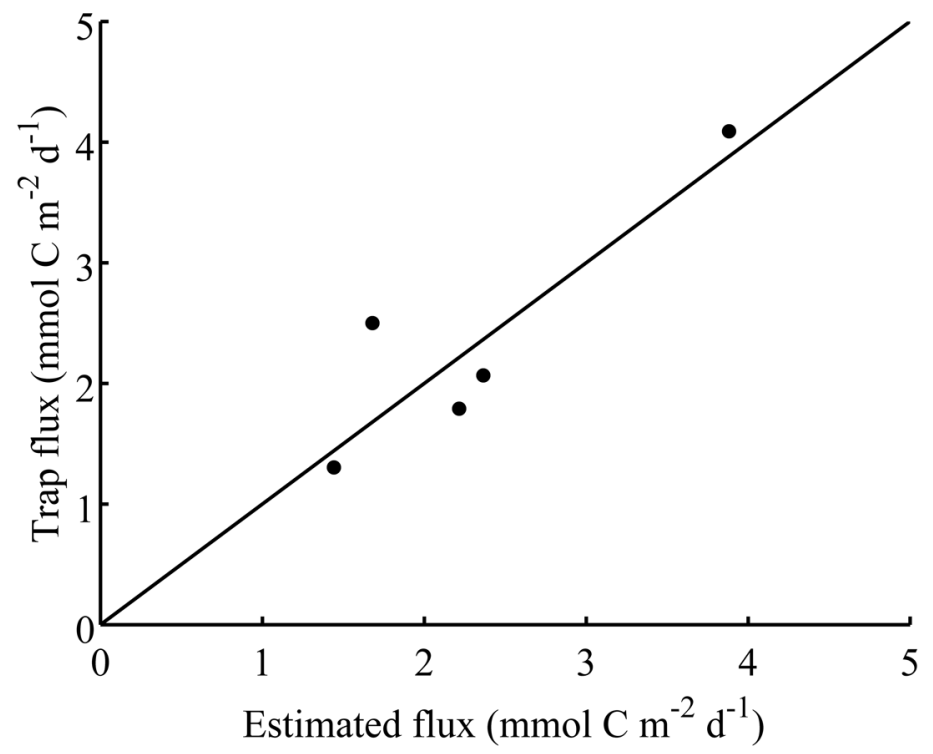

Fig. 3. A comparison of the sinking carbon fluxes measured with the drifting sediment traps $\left(F_{\mathrm{C}}^{\text {trap }}\right)$ and the carbon flux $\left(F_{\mathrm{C}}^{\text {est }}\right)$ estimated from

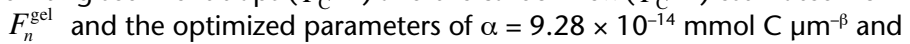
$\beta=3.24$ derived from Eqs. 4 and 5. Data are from the 2009 deployments on $14 \mathrm{Jul}$ and $21 \mathrm{Sep}$ at the BATS site. The solid line represents a 1:1 correlation between the measurements and the estimates.

in color and were likely made primarily of loosely consolidated aggregate material. Thus, the combination of loosely associated aggregate material at the small sizes and the carbon-rich fecal material in the large size classes results in particle carbon contents that increase rapidly through this size range. Because the large particles are not merely larger assemblies of the same elementary material that make up the small particles, a fractal assumption that constrains $\beta$ It might be expected that the large value of $\beta$ would confer sinking velocities that also increase rapidly with respect to size. On the contrary, we found that $w_{\text {avg }}$ remained relatively constant across the size range studied here. This observation could be explained by the fact that $F_{n}^{\text {gel }}$ and $F_{\mathrm{C}}^{\text {trap }}$ (the data used to calculate $\beta$ ) are made up of only the sinking subset of all particles in the water column. So while the carbon density of the sinking particles might increase rapidly as a function of size, it does not necessarily imply that all particles in the water column follow this same behavior. The composition of particles in the trap will be most heavily influenced by the particles that sink rapidly, and the value of $\beta$ will reflect the low carbon content of porosity-accelerated aggregates in the small size classes and the high carbon content of compacted fecal material with elevated excess densities. Conversely, $w_{\text {avg }}$ is the average velocity for all particles in the water column of a given size. Therefore the concomitant presence of large slowly sinking particles in the water column could influence $w_{\text {avg }}$ without having a substantial effect on the parameterization of $m$.

Before applying this method widely, we assess our method's skill at reproducing particle fluxes by applying it to the pro-

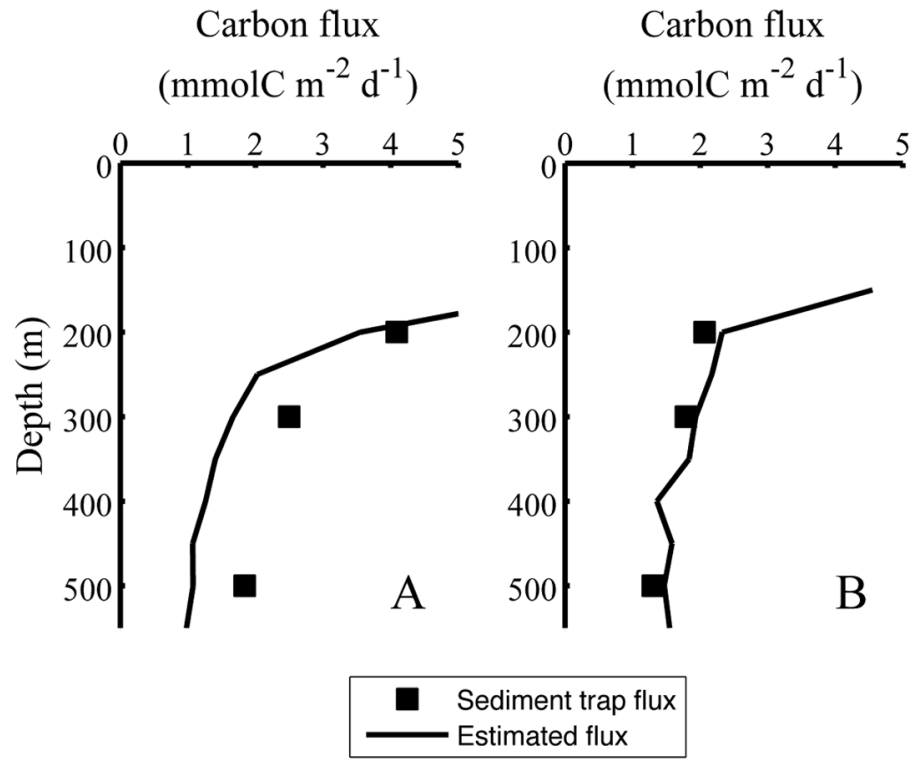

Fig. 4. Sinking carbon flux profiles as measured by the drifting sediment trap arrays (squares) and those estimated from the VPR-derived measurements of the concentration size distribution (lines). These dataestimate comparisons are from the (A) $14 \mathrm{Jul}$ and (B) 21 Sep 2009 deployments at the BATS site.

files of $c_{n}$ measured at the reference sites adjacent to the sediment trap array during July and September of 2009 (no $F_{\mathrm{C}}^{\text {trap }}$ measurements were available for the May deployment). The available $w_{\text {avg }}$ were applied across depth ranges as follows: $w_{\text {avg }}$ measured at $200 \mathrm{~m}$ were applied to depths from 150-200 m, the $w_{\text {avg }}$ from $300 \mathrm{~m}$ were applied to the $250-350 \mathrm{~m}$ depth range, and the $w_{\text {avg }}$ from $500 \mathrm{~m}$ was applied to the depths of 400-550 $\mathrm{m}$. In the specific case of the July validation deployment, a failed polyacrylamide gel trap at $500 \mathrm{~m}$ prevented the calculation of $w_{\text {avg }}$ at this depth, so in this case, $w_{\text {avg }}$ from 300 $\mathrm{m}$ was applied all the way to $550 \mathrm{~m}$.

The results are shown in Fig. 4 where the solid lines indicate the fluxes estimated from the VPR profiles of $c_{n}$ and the square markers represent the carbon flux measured by the bulk flux collecting sediment traps. Note that these results differ slightly from the comparison of $F_{\mathrm{C}}^{\text {est }}$ and $F_{\mathrm{C}}^{\text {trap }}$ in Fig. 3 because the results in Fig. 4 follow the calculation through its entirety from $c_{n}$ to $F_{\mathrm{C}}^{\text {est }}$, whereas those in Fig. 3 are simply determined by computing $F_{\mathrm{C}}^{\text {est }}$ from $F_{n}^{\text {gel }}$ (Eq. 4). Thus, the results presented in Fig. 4 also account for any errors introduced by $w_{\text {avg }}$ during the conversion from $c_{n}$ to $F_{n}^{\text {calc }}$. The results of Fig. 4 demonstrate that the flux estimates are accurate within about $1 \mathrm{mmol} \mathrm{C} \mathrm{m} \mathrm{C}^{-2}$ of those measured with the drifting sediment traps. In 4 of 6 comparisons, the discrepancy is limited to a maximum of $0.2 \mathrm{mmol} \mathrm{C} \mathrm{m}^{-2} \mathrm{~d}^{-1}$. The two largest discrepancies occurred at the 300 and $500 \mathrm{~m}$ depths in the July dataset. Here, the fluxes are underestimated relative to the measured sediment trap fluxes. This discrepancy arises primarily because of the parameterization of car- 
bon flux from $F_{n}^{\text {calc }}$ underestimates the bulk fluxes measured by the sediment trap. This underestimate can be seen as the lone point that falls significantly off the 1:1 line in Fig. 3. The causes of this underestimation could be an increase in the actual particle carbon content at that location, or a polyacrylamide gel trap that undercollected the flux. However, given the fact that even direct measurements from sediment traps are prone to errors of these magnitudes, and these errors were only found in a small subset of the data, the flux estimation method presented here is capable of capturing many important features of the particle flux. Also, as stated above, there was no $w_{\text {avg }}$ data available at $500 \mathrm{~m}$ in the July case, so direct comparison of that point to the estimated fluxes at that depth are not necessarily appropriate because the $w_{\text {avg }}$ used at those depths was taken from measurements of $w_{\text {avg }}$ at $300 \mathrm{~m}$.

In addition to yielding accurate estimates of the flux magnitude, the method validations in Fig. 4 also show some skill at reproducing the rate of flux attenuation with respect to depth. We found that the decrease in flux between 200 and $500 \mathrm{~m}$ was more pronounced during the July occupation of the BATS site whereas the September example showed very little attenuation in this depth range. The flux estimates in Fig. 4 also allow for the discrete measurements of sediment trap fluxes to be contextualized in a higher vertical resolution context. For example, the trap deployments in Fig. 4B did not capture the rapid decrease in flux between 150 and $200 \mathrm{~m}$ during the 21 Sep deployment. Having the extra depth-resolved information provided by the VPR-derived flux estimates thus can avoid misinterpretation of mesopelagic flux attenuation caused by limited sampling at only a few discrete depths.

Guidi et al. (2008) and Iversen et al. (2010) grouped the effects of particle carbon content and sinking velocities into a single power law formulation (Eq. 2) for the calculation of $F_{\mathrm{C}}^{\text {est }}$ directly from measurements of $c_{n}$. To compare the effectiveness of the method presented here to these earlier approaches, we applied both the global (Guidi et al. 2008) and regional Cape Blanc (Iversen et al. 2010) parameterizations of $A$ and $b$ to our measurements of $c_{n}$ at the BATS site to calculate independent estimates of flux. In addition, we also used the Guidi et al. (2008) methodology to calculate our own local BATS parameterization of Eq. 2, yielding the parameters $A=8.99 \times 10^{-6} \mathrm{mmol}$ $\mathrm{C} \mathrm{m} \mathrm{d}^{-1} \mu \mathrm{m}^{-b}$ and $b=1.22$. Fig. 5 displays the resulting flux estimates for the four different methods/parameterizations and compares them to the fluxes measured directly by the sediment traps (data also available in Table 6). This comparison reveals that the two locally calibrated approaches (this study and the BATS parameterization of $m \cdot w_{\text {avg }}$ ) are the most accurate at reproducing the measured fluxes. The Guidi et al. (2008) parameterization relies on pairs of $F_{\mathrm{C}}^{\text {trap }}$ and $c_{n}$ data from calibration sites around the globe. Using this parameterization, their method underestimated the flux at BATS by a factor of about 10 . Iversen et al. (2010) found a similar $10 \times$ offset when the Guidi et al.

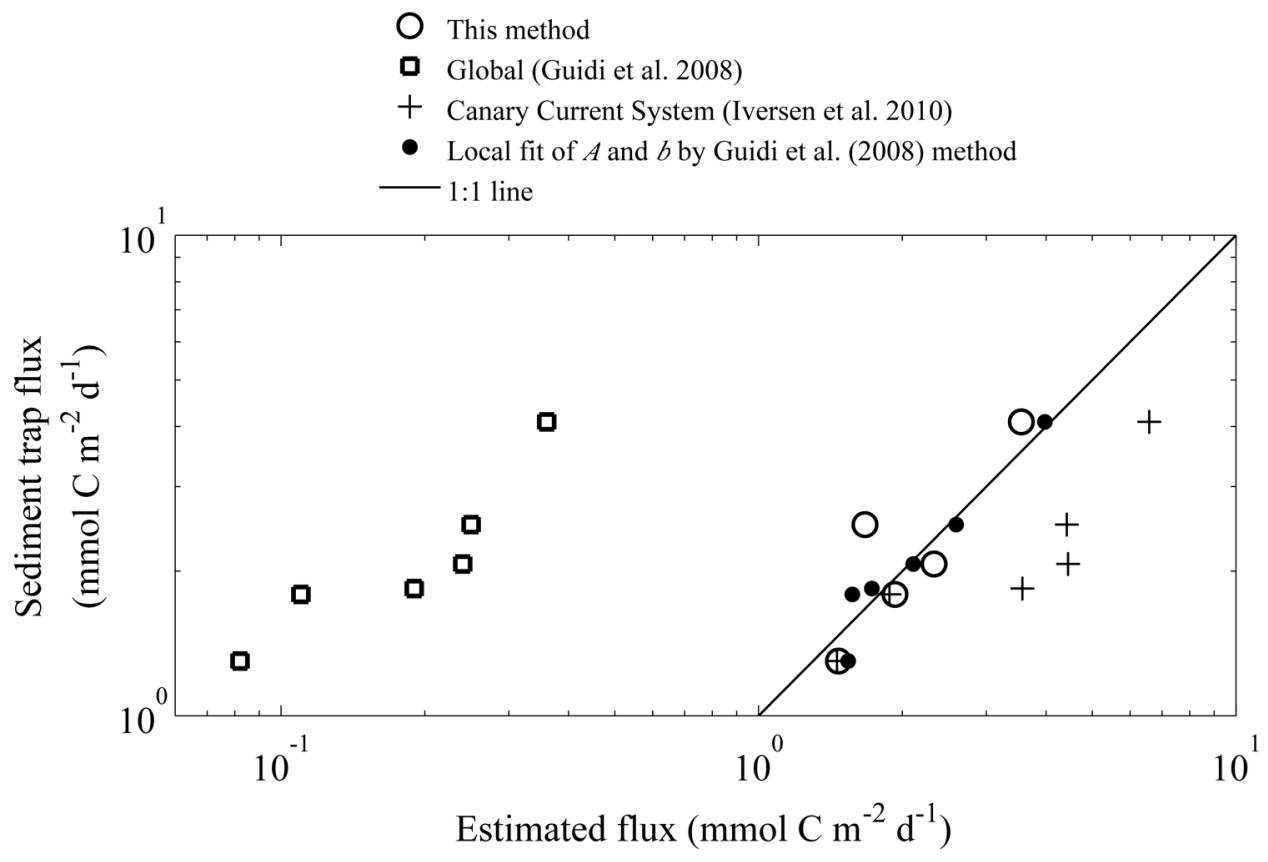

Fig. 5. Carbon fluxes estimated from various methods and parameterizations compared with measurements made by drifting sediment traps. The Guidi et al. (2008) parameterization is based off of global dataset whereas the Iversen et al. (2010) parameterization is from the Canary Current System. Those parameterizations use a single power law relationship between the $c_{n}$ and the carbon flux, whereas the method described in this study uses distinct local calibrations of the average sinking velocity and particle carbon content as a function of the particle size. A local fit of our data at the BATS site using the Guidi et al. (2008) method is also shown. The $c_{n}$ data used to calculate these values are from the 14 Jul 2009 and 21 Sep 2009 deployments of the VPR at the BATS site. 
(2008) parameterization was applied to $c_{n}$ data that they collected off of Cape Blanc, Mauritania so they elected to use a locally calibrated parameterization of $m \cdot w_{\text {avg }}$. When the Iversen et al. (2010) parameterization from Cape Blanc was applied to our measurements of the $c_{n}$ at BATS, the accuracy was improved relative to the global formulation, but still overestimated the carbon flux by a factor of about 2 in a majority of the cases tested here. The two local approaches (this method and the direct $m \cdot w_{\text {avg }}$ parameterization) minimized the errors between the estimated flux and the sediment trap measurements.

There are two primary reasons that the nonlocal parameterizations of Guidi et al. (2008) and Iversen et al. (2010) are relatively unsuccessful at accurately estimating the flux from $c_{n}$ measurements at BATS. First, as mentioned in the introduction, the parameterizations do not account for spatial or temporal variability in the $w_{\text {avg }}$ or carbon content. While the Guidi et al. (2008) method draws its parameterization from a variety of different ocean regions around the globe, it is not necessarily capable of accurately estimating the fluxes at locations where $w_{\text {avg }}$ and carbon content differ from the global average. Similarly, the parameterization derived from data off of Cape Blanc (Iversen et al. 2010) is not well suited for application at BATS.

The second reason why the nonlocal parameterizations are unsuccessful when applied to the $c_{n}$ data at BATS is because the different in situ imaging instruments used in these studies have not been intercalibrated. Although care has been taken in each case to produce calibrated and accurate $c_{n}$ data, different instruments are likely to yield different results. Each instrument and the custom image analysis software used to calculate $c_{n}$ may have different sensitivities to various particle types or sizes. This instrument-to-instrument variability can only be accounted for when they are deployed side-by-side and rigorously intercalibrated (Jackson et al. 1997; Picheral et al. 2010). However, this approach cannot be implemented on a wide scale, and at present, there is not a standardized method for (inter)-calibrating in situ imaging instruments.

Both of the locally parameterized methods of flux estimation reproduce the measured fluxes with good accuracy. In this particular case study at BATS, the variability in $w_{\text {avg }}$ was small between the different the times and depths sampled (Table 5). This low variability minimized the added benefit of explicitly capturing this variability in $w_{\text {avg }}$ relative to a single parameterization of $m \cdot w_{\text {avg }}$. In regions such as the western Antarctic Peninsula where the variability in $w_{\text {avg }}$ was substantially larger (McDonnell and Buesseler 2010), accounting for this variability using our new method would greatly improve estimates of particle flux from in situ camera systems.

Now that we have assessed the accuracy and effectiveness of this method, we can apply this technique to a high-resolution survey of the $c_{n}$ conducted with the VPR near BATS in September of 2009. The deployment details of each of the 22 VPR casts are recorded in Table 7 . We applied the $w_{\text {avg }}$ deter-

Table 7. Locations and times of VPR deployments conducted in Sep 2009 during the high-resolution survey. These stations served as proxy sites used to demonstrate the utility of this method for estimating sinking particle fluxes from measurements of $c_{n}$.

\begin{tabular}{|c|c|c|c|c|c|c|}
\hline \multirow{2}{*}{$\frac{\text { Cast ID }}{\text { TZEX } 11}$} & \multicolumn{2}{|c|}{ Latitude $(\mathrm{N})$} & \multicolumn{2}{|c|}{ Longitude (W) } & \multirow{2}{*}{$\frac{\text { Date (Sep 2009) }}{24}$} & \multirow{2}{*}{$\begin{array}{c}\text { Time (local) } \\
2: 50\end{array}$} \\
\hline & $31^{\circ}$ & 16.911 & $63^{\circ}$ & 34.677 & & \\
\hline TZEX 12 & $31^{\circ}$ & 24.612 & $63^{\circ}$ & 29.434 & 24 & $5: 20$ \\
\hline TZEX 13 & $31^{\circ}$ & 31.785 & $63^{\circ}$ & 32.667 & 24 & $10: 30$ \\
\hline TZEX 14 & $31^{\circ}$ & 33.399 & $63^{\circ}$ & 35.578 & 24 & $13: 15$ \\
\hline TZEX 15 & $31^{\circ}$ & 45.664 & $63^{\circ}$ & 41.437 & 24 & $15: 54$ \\
\hline TZEX 16 & $31^{\circ}$ & 56.844 & $63^{\circ}$ & 51.33 & 24 & $18: 30$ \\
\hline TZEX 17 & $31^{\circ}$ & 51.108 & $63^{\circ}$ & 58.632 & 24 & $21: 50$ \\
\hline TZEX 18 & $31^{\circ}$ & 47.526 & $64^{\circ}$ & 3.12 & 25 & 0:01 \\
\hline TZEX 19 & $31^{\circ}$ & 44.21 & $64^{\circ}$ & 5.629 & 25 & $2: 15$ \\
\hline TZEX 23 & $31^{\circ}$ & 31.766 & $63^{\circ}$ & 56.09 & 26 & $11: 05$ \\
\hline TZEX 24 & $31^{\circ}$ & 29.19 & $63^{\circ}$ & 52.799 & 26 & $20: 40$ \\
\hline TZEX 25 & $31^{\circ}$ & 21.05 & $63^{\circ}$ & 46.9 & 27 & $10: 55$ \\
\hline TZEX 26 & $31^{\circ}$ & 21.032 & $64^{\circ}$ & 1.391 & 28 & $7: 25$ \\
\hline TZEX 27 & $31^{\circ}$ & 26.58 & $64^{\circ}$ & 2.295 & 28 & $9: 35$ \\
\hline TZEX 28 & $31^{\circ}$ & 32.12 & $64^{\circ}$ & 5.51 & 28 & $11: 45$ \\
\hline TZEX 29 & $31^{\circ}$ & 36.174 & $64^{\circ}$ & 6.93 & 28 & $13: 30$ \\
\hline TZEX 30 & $31^{\circ}$ & 40.128 & $64^{\circ}$ & 9.774 & 28 & $15: 27$ \\
\hline TZEX 31 & $31^{\circ}$ & 35.028 & $64^{\circ}$ & 34.038 & 28 & $18: 38$ \\
\hline TZEX 32 & $31^{\circ}$ & 41.532 & $64^{\circ}$ & 33.738 & 28 & $20: 28$ \\
\hline TZEX 33 & $31^{\circ}$ & 51.6 & $64^{\circ}$ & 32.244 & 28 & $22: 02$ \\
\hline TZEX 34 & $31^{\circ}$ & 51.656 & $64^{\circ}$ & 31.667 & 29 & $0: 05$ \\
\hline TZEX 35 & $31^{\circ}$ & 58.077 & $64^{\circ}$ & 31.292 & 29 & $1: 30$ \\
\hline
\end{tabular}



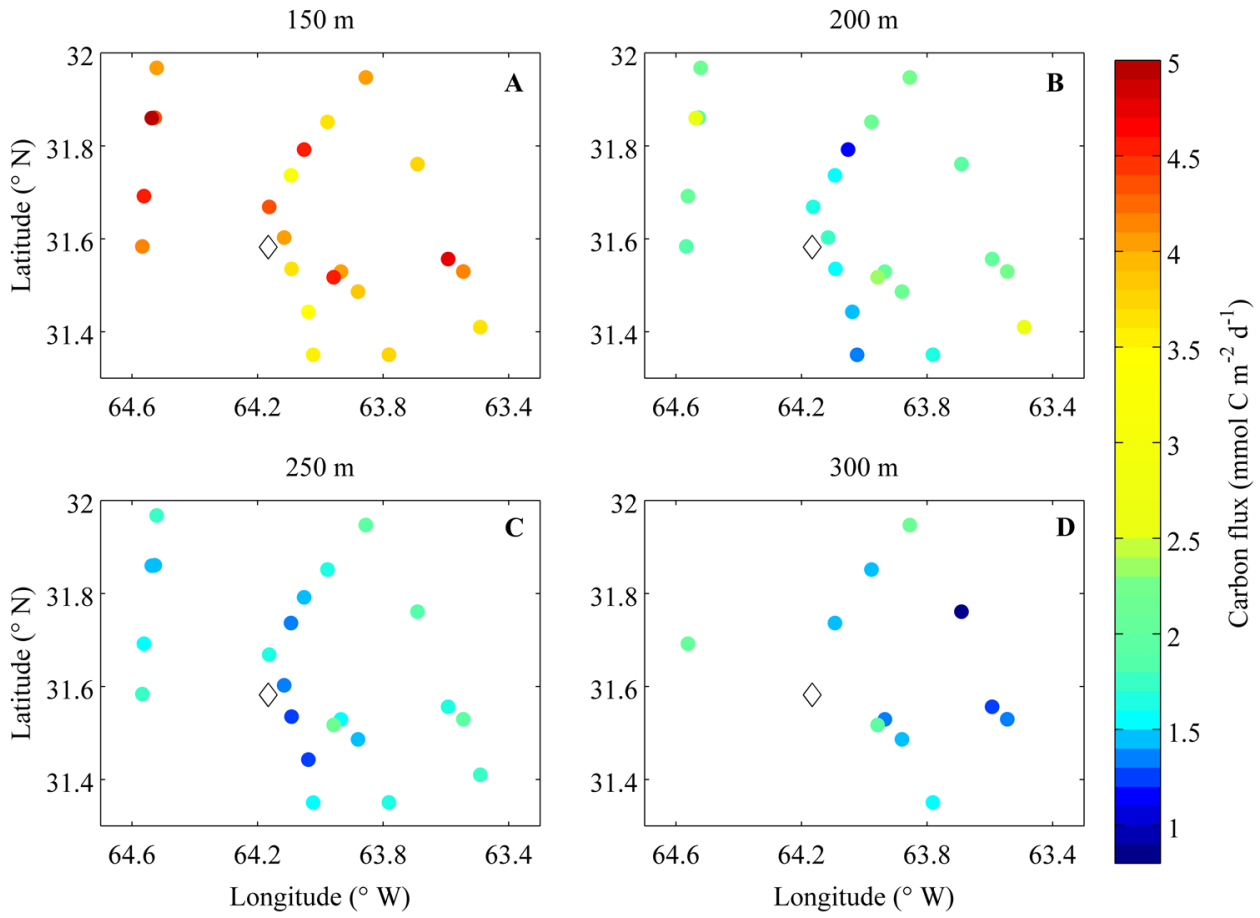

Fig. 6. Maps of the sinking carbon flux $\left(\mathrm{mmol} \mathrm{C} \mathrm{m} \mathrm{m}^{-2} \mathrm{~d}^{-1}\right)$ estimated from measurements of the particle concentration size distribution $c_{n^{\prime}}$ average sinking velocities $w_{\text {avg }}$ and the parameterization of carbon content, $m$. Measurements were made from 24-29 Sep in the BATS region to the southeast of Bermuda. The color of the points represents the magnitude of the estimated flux at the four different depth horizons of (A) $150 \mathrm{~m}$, (B) $200 \mathrm{~m}$, (C) 250 $\mathrm{m}$, and (D) $300 \mathrm{~m}$ below the surface. The open diamonds symbolize the location of the 21 Sep deployment of the drifting sediment trap array used for calibration of $w_{\text {arg }}$ and $m$.

mined from the 21 Sep calibration and the carbon content parameterization (described above) that was determined from a combination of the July and September comparisons between $F_{n}^{\text {gel }}$ and $F_{\mathrm{C}}^{\text {trap }}$.

The results of this high-resolution flux estimation exercise are presented in Fig. 6. In the mesopelagic zone at depths of 150 to $300 \mathrm{~m}$, fluxes ranged from about $1-5 \mathrm{mmol} \mathrm{C} \mathrm{m} \mathrm{m}^{-2} \mathrm{~d}^{-1}$. As is typical throughout much of the oceans, these fluxes were largest just below the euphotic zone and decreased with increasing depth. Many of the profiles only went to a final depth of $250 \mathrm{~m}$, so estimation of flux at deeper depths was not possible in these cases. Where deeper profiles were available, they generally showed fluxes decreasing to at about 1-2 mmol $\mathrm{C} \mathrm{m}^{-2} \mathrm{~d}^{-1}$ in the depths below $250 \mathrm{~m}$. The maps of Fig. 6 reveal the high-resolution structure of particle fluxes in the region of BATS. There are gradients of particle flux along certain transects, as well as patchiness on scales likely smaller than those sampled by the VPR.

Zooplankton were not excluded from the analysis of the VPR images, however their presence is unlikely to affect our reported values of $c_{n}$. By comparing literature values of the numeric abundances of zooplankton in three net size classes $(366,203$, and $76 \mu \mathrm{m})$ equivalent to the sizes sampled by the VPR, we calculated that these zooplankton represent approximately $1 \%, 2.1 \%$, and $2.5 \%$, respectively, of the total particu- late abundance in the mesopelagic waters at BATS (Deevey 1971; McDonnell 2011). Given that these abundances are often within the uncertainty of our measurements of $c_{n}$, we assume that the presence of zooplankton do not significantly affect our results at this location. Visual inspection of thousands of VPR images confirmed that amorphous particulate matter greatly outnumber identifiable zooplankton.

We detected no significant effect of sampling time (day versus night) on the abundances of particles in all of the size classes sampled by the VPR between 150 and $350 \mathrm{~m}(P>0.05)$. This implies that diel vertical migration by zooplankton between the near-surface and deep layers did not have diel effects on the total abundance of particles, either due to the presence of their actual bodies or the particles they produce, consume, or transform.

To better visualize the envelope of flux magnitudes, and their variability with respect to depth, we plotted all the estimated flux profiles together in Fig. 7. Flux variability was largest in the upper mesopelagic zone with fluxes spanning a range of about $2 \mathrm{mmol} \mathrm{C} \mathrm{m} \mathrm{m}^{-2} \mathrm{~d}^{-1}$ at $200 \mathrm{~m}$ depth, $1.5 \mathrm{mmol} \mathrm{C}$ $\mathrm{m}^{-2} \mathrm{~d}^{-1}$ at $300 \mathrm{~m}$, and converging to a smaller range of about $0.5 \mathrm{mmol} \mathrm{C} \mathrm{m} \mathrm{C}^{-2}$ at $600 \mathrm{~m}$. In a few of the estimated flux profiles, there were occasionally slight discontinuities in the calculated flux with respect to depth. These artifacts occurred between the $200-250 \mathrm{~m}$ and $350-400 \mathrm{~m}$ flux estimate pairs, 


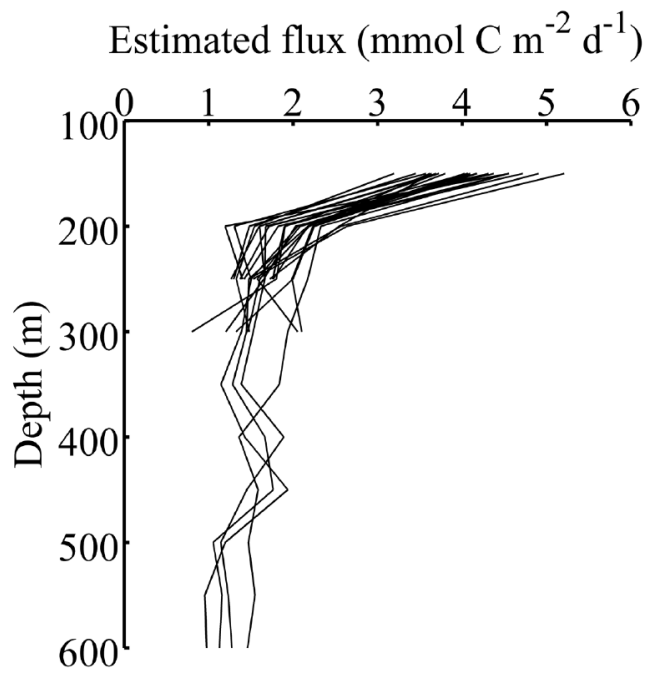

Fig. 7. Estimated sinking particle flux profiles for the BATS region. The flux profiles contain the same estimated fluxes as Fig. 6, but plotted together to show the envelope of flux variability as a function of depth.

corresponding to the discrete boundaries of the applied $w_{\text {avg }}$. Without higher depth-resolved data on the variability of the $w_{\text {avg }}$, we chose to maintain these discrete depth ranges for $w_{\text {avg }}$ application rather than extrapolate between the depths.

This broad envelope of flux variability is nearly identical to the flux magnitudes and variability reported across the annual cycle at BATS (Lohrenz et al. 1992). This finding suggests that the small-scale spatial and temporal features of flux are equally important for the accurate assessment of particle flux and export budgets in the BATS region as are the ongoing time-series measurements consisting of monthly flux measurements at the site (Brix et al. 2006; Helmke et al. 2010; Lomas et al. 2010). This fine-scale spatial and temporal variability is therefore significant enough to obscure emerging trends in multiyear flux records and suggests a need for better resolved quantification of particle fluxes in space and time to avoid potential aliasing problems and improve the ability of time-series programs to detect the ongoing changes in the ocean's carbon cycle.

With the parameterization for carbon content, it is possible to calculate the carbon flux as a function of particle size. This can be done either directly from $F_{n}^{\text {gel }}$ or from $F_{n}^{\text {calc }}$ as estimated throughout the spatial survey. Fig. 8 depicts an example of the carbon fluxes estimated as a function of particle size from three of the polyacrylamide gel traps deployed at 200, 300 , and $500 \mathrm{~m}$ depths. In the upper two traps, the flux was dominated by particles with an equivalent spherical diameter of between 320 and $520 \mu \mathrm{m}$, reaching a maximum flux of above $0.5 \mathrm{mmol} \mathrm{C} \mathrm{m}^{-2} \mathrm{~d}^{-1}$ for that particular size class. Larger and smaller particle size classes contributed less carbon to the total flux. This pattern bears a strong similarity with the mass spectra observed by Stemmann et al. (2004a) in the NW

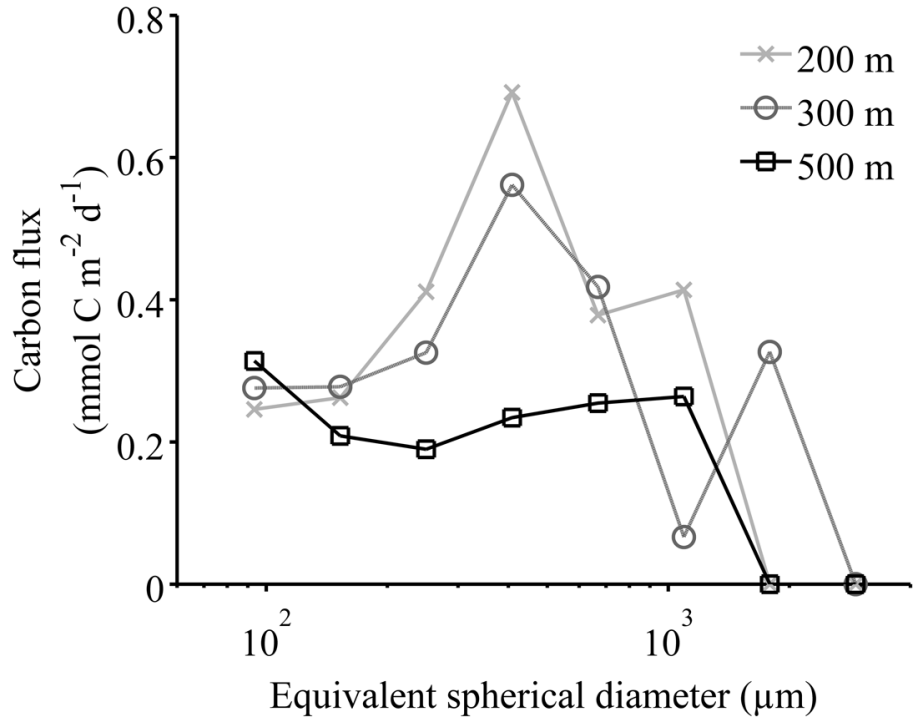

Fig. 8. Estimated carbon flux as a function of particle size for the $21 \mathrm{Sep}$ deployment of the polyacrylamide gel traps at 200,300, and $500 \mathrm{~m}$ depths.

Mediterranean Sea. The decrease in flux with respect to depth was predominantly due to a reduction in the flux of mid-size particles as the carbon flux spectrum became more constant with respect to particle size. By contrast, the flux of the smallest size class increased slightly with respect to increasing depth to become the dominant flux size class by $500 \mathrm{~m}$. These changes reflect the balance between the processes of particle fragmentation, decomposition, and aggregation, consumption, and production that occur on transit from the base of the euphotic zone toward depth. As such, this data and its temporal and spatial variability would offer a valuable constraint on models of marine particle dynamics.

\section{Discussion}

This study highlights the utility of estimating particle fluxes at high spatial and temporal resolutions from in situ measurements of the particle concentration size distribution. The strength of this method is that it relies on local calibrations of $w_{\text {avg }}$ and particle carbon content as a function of particle size.

The ability of this method to quantify the variability in sinking velocities with respect to particle size proved to be very important feature of this method, as $w_{\text {avg }}$ varied in a manner contrary to what is predicted by a simple single parameterization of Stokes' Law. The fact that the magnitudes of the average sinking velocities are significantly slower than those measured along the western Antarctic Peninsula by the same methods (McDonnell and Buesseler 2010) clearly demonstrates the need to account for the variability in $w_{\text {avg }}$ which this method accomplishes.

The use of a single in situ imaging system has its limitations due to the relatively narrow range of particles it is capable of 
detecting. The optics, lighting systems, imaging hardware and software must be carefully chosen to capture the size range of particles that are most important to the process of interest, in this case sinking particle fluxes associated with the ocean's biological pump.

Imaging systems are known to have issues of detection at both ends of the size spectrum. Comparison of camera-derived $c_{n}$ to other methods better suited to measuring size classes smaller than $\sim 100 \mu \mathrm{m}$ indicate that camera systems may underestimate the concentrations of particles at the small end of their detectable size range (Jackson et al. 1997). In the case of the VPR, the particle size corresponding to a single imaging pixel is $21 \mu \mathrm{m}$. However, particles this small are nearly impossible to resolve, and often indistinguishable from image noise. To minimize this issue, we limit our analysis to particles with a diameter larger than $73 \mu \mathrm{m}$. However, even for particles large enough to be projected onto multiple pixels, under detection could remain an issue. As a result, it is possible that our reported $c_{n}$ for particles in the 73-120 $\mu \mathrm{m}$ size class are underestimates of their actual concentration in the water column. The effect on the calculation of $F_{\mathrm{C}}^{\mathrm{est}}$ should be negligible; however, as the methodology described here for parameterizing $w_{\text {avg }}$ accounts for any biases in $c_{n}$ when converting $c_{n}$ to the appropriate $F_{n}^{\text {calc }}$. The measured $F_{n}^{\text {gel }}$ is not expected to have the same problem of small particle under-detection due to the high quality of optics used, the controlled lighting, and high resolution imaging at multiple scales that can better quantify the smallest particles collected in the gel. If the abundances of small particles are underestimated by the VPR, this would result in elevated measurements of $w_{\text {avg }}$ for this size class, and $\mathrm{w}_{\text {avg }}$ would represent more of a conversion factor rather than a physical velocity.

Indeed, many measurements of $w_{\text {avg }}$ including those presented here, do not follow a pattern consistent with a single formulation of Stokes' Law, in which sinking velocities increase monotonically as a function of increasing particle size (McDonnell and Buesseler 2010; Jouandet et al. 2011). These studies observed that the smallest size classes have high velocities relative to some of the larger size classes. Whether this observation is due to an underestimated $c_{n}$ in the small size classes, or is an accurate assessment of the average sinking velocity of all particles in the water column of a given size, remains an outstanding question. McDonnell and Buesseler (2010) proposed a simple model in which the coexistence of two different particle types combined to produce a spectrum of average sinking velocities similar to the observations of $w_{\text {avg }}$. We therefore hypothesize that the observed $w_{\text {avg }}$ at both BATS and along the west Antarctic Peninsula are caused by porous fractal aggregates with accelerated sinking velocities (Johnson et al. 1996) dominating the smaller size classes while primarily nonaggregate fecal material with more conventional Stokes' velocities dominate the fluxes in the larger size classes (Bishop et al. 1980; Bishop et al. 1986). This hypothesis is consistent with the nature of the material observed in the polyacrylamide gels traps (Fig. 2).
On the large end of the size spectrum, the accuracy of particles counts from both the VPR and the gels is primarily limited by the relative scarcity of large particles. We chose to include all of the large particle counts in our analysis, even if very few of them were observed in a given size class. Although this approach means that the errors in the largest size classes can approach $100 \%$, it is better than the alternative of truncating the size spectrum at a smaller size and assuming that the largest observed particles play no role in the concentrations and fluxes of particles. As shown in Fig. 8, a small but non-negligible fraction of the total carbon flux can be attributed to particles with $d>1000 \mu \mathrm{m}$. Therefore, while the uncertainty in the measurement of particle abundance increases at the large end of the size spectrum, their relative contribution to the total carbon flux decreases, thereby limiting the effect of this uncertainty on $F_{\mathrm{C}}^{\text {est }}$.

Prior to this study, the paucity of reliable carbon content measurements remained a large impediment to the accurate estimation of carbon flux from numeric particle abundances or fluxes (Guidi et al. 2007; Ebersbach and Trull 2008). Measurements of carbon content were hampered for decades by the methodological challenges of labor-intensive and depthrestricted collection of particles via meticulous SCUBA techniques in coastal surface waters. Furthermore, as stated by Alldredge (1998), these results from near-surface particles are not likely applicable to particle populations of the meso- and bathypelagic depths. The use of the polyacrylamide gel traps described here circumvents the need for diver collection of individual particles, and accomplishes it in the range of depths appropriate for its application to flux estimation. The direct comparison of the $F_{n}^{\text {gel }}$ and the bulk carbon fluxes measured in the sediment traps represents a new, straightforward, and scalable method for quantifying the carbon content in the inaccessible waters of the mesopelagic.

As mentioned above, the examples and assessments that we provide here use calibrated relationships for the $w_{\text {avg }}$ at different times and depths throughout the study, but only employ a single parameterization for the carbon content. We assume here that carbon content as a function of particle size does not change from May to September at this site and that it is constant within the $150-550 \mathrm{~m}$ depth range considered here. Indeed, it appears that vastly different carbon content or $w_{\text {avg }}$ must have been present above $150 \mathrm{~m}$ because in the euphotic zone, $c_{n}$ were much larger than they were in the mesopelagic. When $w_{\text {avg }}$ and carbon content calculated in the mesopelagic zone were applied to the $c_{n}$ of the euphotic zone, they yielded unrealistically large sinking fluxes in this depth range. Of course the necessary spatial or temporal scales of this assumption could be reduced by increasing the number of drifting trap deployments and therefore the number of comparisons between $F_{n}^{\text {gel }}$ and $F_{\mathrm{C}}^{\text {trap }}$. Perhaps in this manner, changes in carbon content with respect to depth and time of year could be quantified and accounted for in future flux estimations. 
However, robust minimizations of $\Delta F_{\mathrm{C}}$ (Eq. 5), such as the example shown in Fig. 3, require multiple measurements that span a range of flux magnitudes, implying that carbon content parameterizations will still need to be derived from comparisons of $F_{n}^{\text {gel }}$ and the $F_{\mathrm{C}}^{\text {trap }}$ at multiple locations, depths, or times. The additional ship time required for supplementary trap deployments may also limit the attainment of high-resolution estimates of carbon content and $w_{\text {avg }}$ especially on long survey/transect cruises where short station occupations are common.

Unfortunately, the issues of sediment trap collection efficiencies and hydrodynamic biases (Buesseler et al. 2007a) are not avoided through this method because the calibrations and validations of this method are based off of these very techniques. Future applications of this method would benefit from the use of neutrally buoyant sediment traps and their reduced hydrodynamic biases (Buesseler et al. 2000; Lampitt et al. 2008).

The application of this methodology throughout the oceans would improve our understanding of the ocean's biological pump in several ways. As intended, the high resolution of the flux estimates afforded by this method will allow for the assessment of fluxes on temporal and spatial scales previously unresolved by conventional sediment traps. This methodological advancement would make it possible to more accurately assess regional and basin-scale carbon budgets, explore the potential small-scale linkages between sinking particle fluxes and the physical, chemical, and biological properties or processes that control them, and improve our ability to evaluate the effectiveness of ocean iron fertilization as a method for carbon sequestration. Moreover, because this method separately quantifies $w_{\text {avg }}$ and $m$, these new measurements will likely provide novel insights into the mechanisms that control the strength and efficiency of the biological pump throughout the oceans.

\section{Comments and recommendations}

Our method for sinking carbon flux estimation is widely applicable throughout the world's oceans because it is designed to capture the natural variability in the two parameters that influence the conversion between $c_{n}$ and carbon flux. Although it does require the addition of short-term sediment trap deployments and in situ camera profiles to oceanographic cruise schedules, these sampling efforts enable at least an order of magnitude increase in the density and frequency of flux measurements over what is possible with conventional sediment traps alone.

This method and others before it use discrete calibrations of $w_{\text {avg }}$ and $m$ at selected reference stations to extrapolate the flux at other locations where measurements of $c_{n}$ can be made. Naturally, this process relies on the assumptions about the uniformity of $w_{\text {avg }}$ and $m$ over the range of proxy sites where fluxes are estimated. It is therefore imperative that we design future studies to better understand the spatial and temporal scales over which these assumptions are valid. With this knowledge, it will be possible to implement optimal calibration strategies that minimize the uncertainty in flux estimates while maximizing the spatial and temporal coverage of flux estimations that this method can provide.

Because each method for flux estimation has its own strengths and uncertainties, we recommend future studies that combine multiple methodologies, such as drifting sediment traps, neutrally buoyant sediment traps, polyacrylamide gel traps, 234-Th export measurements, and optical methods such as the one described here to measure carbon flux. Horizontal method integration such as this can greatly improve our understanding of both their utility and biases, while helping to promote continued methodological maturation. Vertical integration of this method with other nonparticle flux oceanographic methods is essential to elucidate the connections between particle flux and the physical, chemical, and biological processes that control it.

Future studies should expand the size ranges of particles under consideration. The observations that particles with sizes around $100 \mu \mathrm{m}$ often have high average sinking velocities (McDonnell and Buesseler 2010; Jouandet et al. 2011) needs to be tested by combining data from multiple optical instruments that together can cover a wider spectrum of particle sizes. Because large quantities of these small particles were observed in the polyacrylamide gels, it is clear that they play a significant role in the biological pump. Even if their sinking velocities are slow, smaller particles can serve as source material for larger aggregates and fecal matter with sinking characteristics that render them important to the overall flux (Richardson and Jackson 2007). By accurately quantifying the concentrations of particles smaller than $100 \mu \mathrm{m}$, it would be possible to put improved mass balance constraints on models of particle aggregation and disaggregation (Jackson and Burd 1998). Advances in digital camera resolution, image capture rate, and lighting design has the potential to expand the detection limits of in situ imaging systems, while at the same time, allowing for an expansion of the image volume, thereby reducing the uncertainties associated with the low concentrations of the largest particles.

As in situ imaging technology matures, its utility will expand as it becomes integrated into conventional observational platforms such as ship CTD packages (Picheral et al. 2010). A variety of emergent instrument platforms such as autonomous underwater floats and gliders (Rudnick et al. 2004; Bishop 2009; Johnson et al. 2009), as well as profiling moorings and sensor networks (Doherty et al. 1999; Chave et al. 2004) provide rapidly expanding opportunities for the use of particle sensors to study the dynamics of the ocean's biological pump. Finally, while we focused exclusively on the fluxes of particulate organic carbon, this method could conceivably be applied to a variety of other particulate constituents including nitrogen, phosphorous, biogenic minerals, and trace metals. 


\section{References}

Alldredge, A. 1998. The carbon, nitrogen and mass content of marine snow as a function of aggregate size. Deep Sea Res. I 45:529-541 [doi:10.1016/S0967-0637(97)00048-4].

— marine snow. Limnol. Oceanogr. 33:339-351 [doi:10.4319/ lo.1988.33.3.0339].

Armstrong, R. A., M. L. Peterson, C. Lee, and S. G. Wakeham. 2009. Settling velocity spectra and the ballast ratio hypothesis. Deep Sea Res. II 56:1470-1478 [doi:10.1016/j.dsr2. 2008.11.032].

Benitez-Nelson, C., K. Buesseler, M. R. Van der Loeff, J. Andrews, L. Ball, G. Crossin, and M. Charette. 2001. Testing a new small-volume technique for determining 234-Th in seawater. J. Radioanal. Nucl. Chem. 248:795-799 [doi:10.1023/A:1010621618652].

Berelson, W. M. 2001. The flux of particulate organic carbon into the ocean interior: A comparison of four US JGOFS regional studies. Oceanography 14:59-67 [doi:10.5670/ oceanog.2001.07].

Bishop, J. 2009. Autonomous observations of the ocean biological carbon pump. Oceanography 22:182-193 [doi:10.5670/oceanog.2009.48].

— biomass and flux variability in the Southern Ocean. Global Biogeochem. Cycles 23:GB2019 [doi:10.1029/2008GB00 3206].

Bishop, J. K. B., R. W. Collier, D. R. Kettens, and J. M. Edmond. 1980. The chemistry, biology, and vertical flux of particulate matter from the upper $1500 \mathrm{~m}$ of the Panama Basin. Deep Sea Res. A 27:615-616 [doi:10.1016/0198-0149(80) 90077-1].

— J. C. Stepien, and P. H. Wiebe. 1986. Particulate matter distributions, chemistry and flux in the Panama Basin: response to environment forcing. Progr. Oceanogr. 17:1-59 [doi:10.1016/0079-6611(86)90024-8].

-, T. J. Wood, R. E. Davis, and J. T. Sherman. 2004. Robotic observations of enhanced carbon biomass and export at $55^{\circ} \mathrm{S}$ during SOFeX. Science 304:417 [doi:10.1126/science.1087717].

Brew, H., S. Moran, M. Lomas, and A. Burd. 2009. Plankton community composition, organic carbon and thorium-234 particle size distributions, and particle export in the Sargasso Sea. J. Mar. Res. 67:845-868 [doi:10.1357/00222400 9792006124].

Brix, H., N. Gruber, D. M. Karl, and N. R. Bates. 2006. On the relationships between primary, net community, and export production in subtropical gyres. Deep Sea Res. Part II 53:698-717 [doi:10.1016/j.dsr2.2006.01.024].

Buesseler, K., and P. Boyd. 2009. Shedding light on processes that control particle export and flux attenuation in the twilight zone of the open ocean. Limnol. Oceanogr. 54:12101232 [doi:10.4319/lo.2009.54.4.1210].
Buesseler, K. O., D. K. Steinberg, A. F. Michaels, R. J. Johnson, J. E. Andrews, J. R. Valdes, and J. F. Price. 2000. A comparison of the quantity and composition of material caught in a neutrally buoyant versus surface-tethered sediment trap. Deep Sea Res. I 47:277-294 [doi:10.1016/S0967-0637(99) 00056-4].

ment traps for estimating upper ocean particle fluxes. J. Mar. Res. 65:345-416.

- , and others. 2007b. Revisiting carbon flux through the ocean's twilight zone. science 316:567 [doi:10.1126/science. 1137959].

, S. Pike, K. Maiti, C. H. Lamborg, D. A. Siegel, and T. W. Trull. 2009. Thorium-234 as a tracer of spatial, temporal and vertical variability in particle flux in the North Pacific. Deep Sea Res. I 56:1143-1167 [doi:10.1016/j.dsr.2009.04.001]. Chave, A. D., G. Waterworth, A. R. Maffei, and G. Massion. 2004. Cabled ocean observatory systems. Mar. Technol. Soc. J. 38:30-43 [doi:10.4031/002533204787522785].

Conte, M. H., N. Ralph, and E. H. Ross. 2001. Seasonal and interannual variability in deep ocean particle fluxes at the Oceanic Flux Program (OFP)/Bermuda Atlantic Time Series (BATS) site in the western Sargasso Sea near Bermuda. Deep Sea Res. II 48:1471-1505 [doi:10.1016/S0967-0645(00) 00150-8].

Davis, C. S., Gallager, S. M., Marra, M., and W. K. Stewart. 1996. Rapid visualization of plankton abundance and taxonomic composition using the Video Plankton Recorder. Deep Sea Res. II: Topical Studies in Oceanography 43:19471970 [doi:10.1016/S0967-0645(96)00051-3].

Deevey, G. 1971. The annual cycle in quantity and composition of the zooplankton of the Sargasso Sea off Bermuda. I. The upper $500 \mathrm{~m}$. Limnol. Oceanogr. 16:219-240 [doi:10.4319/lo.1971.16.2.0219].

Deuser, W., and E. Ross. 1980. Seasonal change in the flux of organic carbon to the deep Sargasso Sea. Nature 283:364365 [doi:10.1038/283364a0].

, E. Ross, and R. Anderson. 1981. Seasonality in the supply of sediment to the deep Sargasso Sea and implications for the rapid transfer of matter to the deep ocean. Deep Sea Res. A 28:495-505 [doi:10.1016/0198-0149(81)90140-0].

Doherty, K., D. Frye, S. Liberatore, and J. Toole. 1999. A moored profiling instrument. J. Atmos. Ocean. Technol. 16:1816-1829 [doi:10.1175/1520-0426(1999)016<1816:AM $\mathrm{PI}>2.0 . \mathrm{CO} ; 2]$.

Ebersbach, F., and T. Trull. 2008. Sinking particle properties from polyacrylamide gels during the KErguelen Ocean and Plateau compared Study (KEOPS): Zooplankton control of carbon export in an area of persistent natural iron inputs in the Southern Ocean. Limnol. Oceanogr. 53:212-224 [doi:10.4319/lo.2008.53.1.0212].

Guidi, L., L. Stemmann, L. Legendre, M. Picheral, L. Prieur, and G. Gorsky. 2007. Vertical distribution of aggregates $(>110 \mu \mathrm{m})$ and mesoscale activity in the northeastern 
Atlantic: Effects on the deep vertical export of surface carbon. Limnol. Oceanogr. 52:7-18 [doi:10.4319/1o.2007.52.1. 0007].

-, G. Jackson, L. Stemmann, J. Miquel, M. Picheral, and G. Gorsky. 2008. Relationship between particle size distribution and flux in the mesopelagic zone. Deep-Sea Res. I 55:1364-1374 [doi:10.1016/j.dsr.2008.05.014].

Helmke, P., S. Neuer, M. W. Lomas, M. Conte, and T. Freudenthal. 2010. Cross-basin differences in particulate organic carbon export and flux attenuation in the subtropical North Atlantic gyre. Deep Sea Res. I 57:213-227 [doi:10.1016/j.dsr.2009.11.001].

Howard, M. T., A. M. E. Winguth, C. Klaas, and E. MaierReimer. 2006. Sensitivity of ocean carbon tracer distributions to particulate organic flux parameterizations. Global Biogeochem. Cycles 20:GB3011 [doi:10.1029/2005GB00 2499].

Iversen, M. H., N. Nowald, H. Ploug, G. A. Jackson, and G. Fischer. 2010. High resolution profiles of vertical particulate organic matter export off Cape Blanc, Mauritania: Degradation processes and ballasting effects. Deep Sea Res. I 57:771784 [doi:10.1016/j.dsr.2010.03.007].

Jackson, G. A., R. Maffione, D. K. Costello, A. L. Alldredge, B. E. Logan, and H. G. Dam. 1997. Particle size spectra between $1 \mu \mathrm{m}$ and $1 \mathrm{~cm}$ at Monterey Bay determined using multiple instruments. Deep Sea Res. I 44:1739-1767 [doi:10.1016/S0967-0637(97)00029-0].

- , and A. B. Burd. 1998. Aggregation in the marine environment. Environ. Sci. Technol. 32:2805-2814 [doi:10.1021/es980251w].

Johnson, C. P., X. Li, and B. E. Logan. 1996. Settling velocities of fractal aggregates. Environ. Sci. Technol. 30:1911-1918 [doi:10.1021/es950604g].

Johnson, K. S., and others. 2009. Observing biogeochemical cycles at global scales with profiling floats and gliders: Prospects for a global array. Oceanography 22:216-225 [doi:10.5670/oceanog.2009.81].

Jouandet, M. P., T. W. Trull, L. Guidi, M. Picheral, F. Ebersbach, L. Stemmann, and S. Blain. 2011. Optical imaging of mesopelagic particles indicates deep carbon flux beneath a natural iron-fertilized bloom in the Southern Ocean. Limnol. Oceanogr. 56:1130-1140 [doi:10.4319/lo.2011.56.3. 1130].

Karl, D. M., G. A. Knauer, and J. H. Martin. 1988. Downward flux of particulate organic matter in the ocean: a particle decomposition paradox. Nature 332:438-441 [doi:10.1038/ 332438a0].

Knauer, G., and V. Asper. 1989. Report of the U.S. GOFS Working Group on sediment trap technology and sampling. U.S. GOFS Planning Report 10.

Kwon, E., F. Primeau, and J. Sarmiento. 2009. The impact of remineralization depth on the air-sea carbon balance. Nature Geosci. 2:630-635 [doi:10.1038/ngeo612].

Lamborg, C., and others. 2008. The flux of bio-and lithogenic material associated with sinking particles in the mesopelagic 'twilight zone' of the northwest and North Central Pacific Ocean. Deep Sea Res. II 55:1540-1563 [doi:10.1016/j.dsr2.2008.04.011].

Lampitt, R., and others. 2008. Particle export from the euphotic zone: Estimates using a novel drifting sediment trap, 234Th and new production. Deep Sea Res. I 55:14841502 [doi:10.1016/j.dsr.2008.07.002].

Logan, B. E., and D. B. Wilkinson. 1990. Fractal geometry of marine snow and other biological aggregates. Limnol. Oceanogr. 35:130-136 [doi:10.4319/lo.1990.35.1.0130].

Lohrenz, S. E., G. A. Knauer, V. L. Asper, M. Tuel, A. F. Michaels, and A. H. Knap. 1992. Seasonal variability in primary production and particle flux in the northwestern Sargasso Sea: US JGOFS Bermuda Atlantic Time-series Study. Deep Sea Res. A 39:1373-1391 [doi:10.1016/0198-0149(92) 90074-4].

Lomas, M., D. Steinberg, T. Dickey, C. Carlson, N. Nelson, R. Condon, and N. Bates. 2010. Increased ocean carbon export in the Sargasso Sea linked to climate variability is countered by its enhanced mesopelagic attenuation. Biogeosciences 7:57-70 [doi:10.5194/bg-7-57-2010].

- , and S. Moran. 2011. Evidence for aggregation and export of cyanobacteria and nano-eukaryotes from the Sargasso Sea euphotic zone. Biogeosciences 8:203-216 [doi:10.5194/bg-8-203-2011].

Lundsgaard, C. 1995. Use of a high viscosity medium in studies of aggregates, In: Floderus, S., Heisakanen, A.S., Oleson, M., and P. Wassman (Eds.), Sediment trap studies in the Nordic countries. 3. Proceedings of the Symposium on Season Dynamics of Planktonic Ecosystems and Sedimentation in Coastal Nordic Waters. Finnish Environment Agency, pp. 141-152.

Lutz, M., R. Dunbar, and K. Caldeira. 2002. Regional variability in the vertical flux of particulate organic carbon in the ocean interior. Global Biogeochem. Cycles 16:10.1029.

Maiti, K., C. Benitez-Nelson, and K. Buesseler. 2010. Insights into particle formation and remineralization using the short-lived radionuclide, Thoruim-234. Geophys. Res. Lett. 37:L15608 [doi:10.1029/2010GL044063].

Marinov, I., M. Follows, A. Gnanadesikan, J. L. Sarmiento, and R. D. Slater. 2008. How does ocean biology affect atmospheric pCO2? Theory and models. J. Geophys. Res. 113:C07032 [doi:10.1029/2007JC004598].

Matsumoto, K. 2007. Biology-mediated temperature control on atmospheric pCO2 and ocean biogeochemistry. Geophys. Res. Lett. 34:L20605 [doi:10.1029/2007GL031301].

McDonnell, A. M. P. 2011. Marine particle dynamics: sinking velocities, size distributions, fluxes, and microbial degradation rates. PhD thesis, Massachusetts Institute of Technology/Woods Hole Oceanographic Institution.

, and K. O. Buesseler. 2010. Variability in the average sinking velocity of marine particles. Limnol. Oceanogr. 55:2085-2096 [doi:10.4319/lo.2010.55.5.2085]. 
Picheral, M., L. Guidi, L. Stemmann, D. M. Karl, G. Iddaoud, and G. Gorsky. 2010. The Underwater Vision Profiler 5: An advanced instrument for high spatial resolution studies of particle size spectra and zooplankton. Limnol. Oceanogr. Methods 8:462-473 [doi:10.4319/lom.2010.8.462].

Richardson, T. L., and G. A. Jackson. 2007. Small phytoplankton and carbon export from the surface ocean. Science 315:838 [doi:10.1126/science.1133471].

Rudnick, D. L., R. E. Davis, C. C. Eriksen, D. M. Fratantoni, and M. J. Perry. 2004. Underwater gliders for ocean research. Mar. Technol. Soc. J. 38:73-84 [doi:10.4031/0025 33204787522703].

Sarmiento, J., and J. Toggweiler. 1984. A new model for the role of the oceans in determining atmospheric pCO2. Nature 308:621-624 [doi:10.1038/308621a0].

Steinberg, D. K., C. A. Carlson, N. R. Bates, R. J. Johnson, A. F. Michaels, and A. H. Knap. 2001. Overview of the US JGOFS Bermuda Atlantic Time-series Study (BATS): a decade-scale look at ocean biology and biogeochemistry. Deep-Sea Res. II 48:1405-1447 [doi:10.1016/S0967-0645(00)00148-X].

Stemmann, L., G. A. Jackson, and G. Gorsky. 2004a. A vertical model of particle size distributions and fluxes in the midwater column that includes biological and physical processes-Part II: application to a three year survey in the NW Mediterranean Sea. Deep Sea Res. I 51:885-908 [doi:10.1016/j.dsr.2004.03.002].
- - , and D. Ianson. 2004b. A vertical model of particle size distributions and fluxes in the midwater column that includes biological and physical processes-Part I: model formulation. Deep-Sea Res. I 51:865-884 [doi:10.1016/j.dsr.2004.03.001].

Turner, J. T. 2002. Zooplankton fecal pellets, marine snow and sinking phytoplankton blooms. Aquat. Microb. Ecol. 27:57102 [doi:10.3354/ame027057].

Waite, A., and S. Nodder. 2001. The effect of in situ iron addition on the sinking rates and export flux of Southern Ocean diatoms. Deep-Sea Res. Part II 48:2635-2654 [doi:10.1016/S0967-0645(01)00012-1].

Wilson, S., and D. Steinberg. 2010. Autotrophic picoplankton in mesozooplankton guts: evidence of aggregate feeding in the mesopelagic zone and export of small phytoplankton. Mar. Ecol. Progr. Ser. 412:11-27 [doi:10.3354/meps0864].

Yamanaka, Y., and E. Tajika. 1996. The role of the vertical fluxes of particulate organic matter and calcite in the oceanic carbon cycle: Studies using an ocean biogeochemical general circulation model. Global Biogeochem. Cycles 10:361-382 [doi:10.1029/96GB00634].

Submitted 21 September 2011

Revised 10 March 2012

Accepted 6 April 2012 